\title{
DATA ON ULTRA-VIOLET SOLAR RADIATION AND THE SOLARIZATION OF WINDOW MATERIALS
}

\author{
By W. W. Coblentz and R. Stair
}

ABSTRACT

In this paper the following topics are discussed:

1. The variation of ultra-violet solar radiation, available for therapeutic purposes, as dependent upon the time of the day, the season of the year, the altitude and geographic latitude of the station, the pollution of the atmosphere by smoke, etc.

By four methods of attack, data are presented on the amount of ultra-violet solar radiation, used in the treatment of rickets, shut out by common window glass. It is shown that on the clearest days, at the noon hour in summer, at sea-level stations, in the latitude of Washington $\left(38^{\circ} 56^{\prime}\right)$ the amount of ultraviolet solar radiation useful for pereventing rickets amounts to less than 0.3 per cent of the total incident solar rays, or less than about $0.004 \mathrm{~g} \mathrm{cal} . / \mathrm{cm}^{2} / \mathrm{min}$., decreasing to an imperceptible value at unsrise and during cloudy weather.

2. The newly developed window glasses and glass substitutes for transmitting the short wave length ultra-violet solar radiation that is obstructed by common window glass, and their use on different sides (north, south) of a solarium. References are cited showing the futility of using a small window exposed to the north sky for therapeutic purposes.

Data are given showing that, with variation of the angle of incidence of the solar rays from normal upon a solarium, during the year and during the day, the amount transmitted through the glass varies (decreases) by about 20 per cent, as the result of variation in reflection from the surface, and an increase in the optical path of the rays through the glass. This is considered of minor importance in comparison with the question of keeping the glass clean and free from dust, which may reduce the transmission of these rays by 30 to 40 per cent.

Data are given on heavy, double-thickness (one-fourth inch, $6 \mathrm{~mm}$ ) wired glass showing that the transmission of such material at $302 \mathrm{~m} \mu$, after complete solarization, amounts to only 3 to 5 per cent, which is probably too low for therapeutic use. Hence, a glass of single thickness, with a wire mesh under it for safety from breakage, is recommended for solarium roofs.

3. The decrease in transmission of short wave length ultra-violet radiation which occurs in the newly developed glasses and glass substitutes as a result of exposure to the ultra-violet radiation from artificial sources and from the sun.

Data are presented on the decrease in transmission of Corex, Helioglass, Vitaglass, Celoglass, and a number of less commonly known glasses which occurs on exposure to the mercury arc, to the carbon arc with and without a glass chimney, and to the sun at high altitudes and at sea level.

It is shown that these glasses, in thicknesses of $2.3 \mathrm{~mm}$ (marketed prior to February 1, 1929) may be divided into six groups, according to their transmissive properties at $302 \mathrm{~m} \mu$ after solarization: (a) Common window glass and Quartzlite having a transmission less than 1 per cent; (b) Vitaglass, Sanalux and Renovic, transmission about 25 per cent; (c) Holviglass, Sunlit, and Sendlinger's ultraviolet glass, transmission 35 to 40 per cent; (d) Helioglass, Uviol-Jena, and Neuglas, transmission 45 to 50 per cent; (e) Corex-D glass, transmission 60 to 65 per cent; and $(f)$ Corex-G981FF² and Quartz glass, 80 to 90 per cent. 


\section{CONTENTS}

I. Introduction

1. Concerning methods of making the observations

II. Some determinations of the ultra-violet solar radiation shut out by common window glass

III. Effect of solarization upon the ultra-violet transmission of window glasses

1. Methods of photochemical stabilization

2. Effect of temperature upon the solarization of window glasses. . .

3. Rejuvenation of glasses..... 647

4. Vitaglass _........... 648

(a) Effect of sunlight

(b) Effect of artificial light_......... 651

(c) Infra-red transmission

5. Helioglass

(a) Effect of artificial light

656

(b) Effect of sunlight

656

657

6. Corex-A glass

660

(a) Effect of sunlight

660

(b) Effect of artificial light

7. Corex-G981FF ${ }^{2}$

661

8. Corex-D glass

661

9. Ultra-violet filters

662

663

10. Quartz glass . . 663

11. Locke glass _.

12. Quartzlite glass

13. Window glass and bottle glass

14. Holviglass

15. Sunlit._. 666

16. Neuglas.

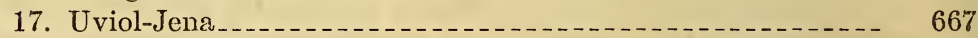

18. Ultra-violet glass _ _ _

19. Miscellaneous new glasses

20. Discussion of results on solarization ............ 668

IV. Effect of solarization upon the ultra-violet transmission of substitutes for window glass.

1. Flexoglass

2. Celoglass $\ldots \ldots$

(a) Accelerated aging under artificial light_........ 676

(b) Exposure to sunlight _._._._. 677

(c) Exposure to weather.

3. Cellophane

4. Pollopas, aldur, gelatin

5. Tracing cloth.... 681

V. Concerning the use of windows

VI. Summary

VII, References_..... 687 


\section{INTRODUCTION}

It is well known that common window glass shuts out completely the ultra-violet rays in sunlight of wave lengths less than about $310 \mathrm{~m} \mu$. Biologists have found that these ultra-violet rays, which are shut out by common window glass, have a special healing value in preventing rickets, whence the name "antirachitic rays." Data will be cited presently showing that, in sunlight, this spectral range of antirachitic activity is only about 5 to $10 \mathrm{~m} \mu$ in width, and has its maximum activity at about $302 \mathrm{~m} \mu$. Hence, in this paper the physical designation "302-region" is used in place of the biological designations "antirachitic rays," "vital rays," etc., used by various writers.

Some years ago special window glasses were put on the market for transmitting the short wave length ultra-violet rays of the solar spectrum, shut out by common window glass. Early in the spring of 1927, reports came to this bureau that these glasses appeared to be losing their transparency as the result of "solarization," which is the designation of the photochemical reaction most of these glasses undergo on exposure to sunlight.

Owing to the importance of this question to the public, an investigation was instituted and a preliminary report issued (1). ${ }^{1}$

Since then several reports have been prepared (2) summarizing the information available on the properties of light sources and window materials used for therapeutic purposes; also the correlation between the biological data and the physical measurements, etc. The reader is referred to these papers for extensive information not given in the present communication, which deals primarily with the decrease in transmission of ultra-violet radiation that occurs in these newly developed window materials as the result of exposure to ultraviolet radiation from artificial sources and from the sun.

At the present time much attention is being given to the development of window materials for transmitting the short wave length ultra-violet rays of the sun, for the purpose of preventing rickets. In fact, the development of new glasses is so rapid that this paper can not claim completeness of discussion of this subject.

On the other hand, because of the variability of sunlight and, hence, the difficulty of standardizing its intensity, attention is being given to the use of artificial sources, especially the carbon arc and the quartz mercury arc lamp. However, since the shortest ultraviolet rays, emitted by these artificial sources of radiation, appear to be unsuitable for the activation of foods (3), etc., it is considered desirable in such cases to cover the arc with a screen which transmits only wave lengths longer than about $290 \mathrm{~m} \mu$; that is to say, the wave lengths which occur in sunlight.

\footnotetext{
1 Figures in parentheses here and throughout the text indicate references given at the end of this paper.
} 
In view of this situation, the data presented in this paper are to be considered from two viewpoints: (a) The applicability of these glasses as window material of high transparency for transmitting the short wave length ultra-violet rays of the solar spectrum, and $(b)$ similarly as filters for use with artificial sources to obstruct the ultra-violet rays of wave lengths less than about $290 \mathrm{~m} \mu$ which are found to be destructive (3) to vitamin $\mathrm{D}$, the active principle that is recognized by biologists as having a beneficial effect in preventing rickets. The information presented will be useful also to those who have purchased special window glasses and desire to know the probable transparency of these glasses after solarization.

\section{CONCERNING THE METHODS OF MAKING THE OBSERVATIONS}

In the present investigation the methods of determining the spectral transmissions are essentially the same as those used in previous work. The ultra-violet transmissions were determined by means of a quartz spectroradiometer (4) of high light gathering power and a portable vacuum thermopile (5) of bismuth-silver, connected with an ironclad galvanometer (6).

The source of radiation was a quartz mercury arc lamp which has numerous intense emission lines (notably at 280, 297, 302, 313, 334, and $365 \mathrm{~m} \mu$ ) conveniently distributed throughout the ultra-violet. It has but little infra-red and visible radiation to diffuse over the ultra-violet spectrum. The presence of scattered, long wave-length radiation is a serious matter when making transmission measurements amounting to less than 1 per cent in the spectral region of wave lengths less than $302 \mathrm{~m} \mu$, an intense emission line in the mercury arc. To eliminate completely the effect of diffuse radiation of long wave lengths a shutter of clear window glass was used when making measurements at wave lengths less than $302 \mathrm{~m} \mu$, and a shutter of red glass (Noviol C would be better) for measurements in the spectral region of 313 to $436 \mathrm{~m} \mu$.

The infra-red measurements were made with a mirror spectroradiometer and the above-mentioned portable vacuum thermopile.

In the present investigation the transmission of numerous samples of various kinds of window glass was determined throughout the whole ultra-violet spectrum. In the meantime there was a marked increase in the demand for transmission measurements on newly developed window glasses, before and after solarization. The necessity, therefore, arose to simplify the methods of testing the transmissions. In this connection it is of interest to note that biological researches show that the strong emission line at $313 \mathrm{~m} \mu$ has only a slight (7) or a doubtful (8) value in preventing rickets and that ultra-violet rays of longer wave lengths have no antirachitic effect, while radiation of wave lengths 297 to $302 \mathrm{~m} \mu$ have a marked 
antirachitic potency. Since, as will be noticed presently, in the wintertime the short wave-length limit of solar radiation is about $305 \mathrm{~m} \mu$, it appears that the spectral range of ultra-violet solar radiation, useful for therapeutic purposes in preventing rickets, is only about 5 to $10 \mathrm{~m} \mu$ in width.

From these biological data and from the similarity of the transmissions of all of these new window glasses in the spectral range from 280 to $365 \mathrm{~m} \mu$ we have concluded that the efficiency of a window glass for transmitting the short wave length ultra-violet solar rays, which have a therapeutic value in preventing rickets, may be determined by confining the measurements to the wave length at $302 \mathrm{~m} \mu$. Hence, the recent measurements reported upon in this paper have been made almost entirely on the emission lines at 297 and $302 \mathrm{~m} \mu$, and it is intended to make future measurements and specifications solely on the emission lines of mercury at $302 \mathrm{~m} \mu$.

There appears to be a tendency among some distributors of these ultra-violet transmitting window glasses to include $320 \mathrm{~m} \mu$ or even longer wave lengths of the ultra-violet in the spectral range of therapeutic activity. However, the inclusion of ultra-violet of wave lengths $320 \mathrm{~m} \mu$ or longer leads to an incorrect appraisal as it gives a higher average transmission than seems warranted when it is recognized that the greatest therapeutic activity occurs in the 302-range of wave lengths shut out by common window glass. Furthermore, since different samples of common window glass transmit from 2 to 20 per cent at $320 \mathrm{~m} \mu$, there is no special reason for including this wave length in the specification of these ultra-violet transmitting glasses. The real value of these special glasses is owing to their superiority for transmitting the solar rays in the spectral region of $302 \mathrm{~m} \mu$. If the rays at $320 \mathrm{~m} \mu$ (which have a relatively high intensity-five to ten times that at $302 \mathrm{~m} \mu$ ) had a special healing value, there would be no need of using special ultra-violet transmitting glass instead of selecting the least greenish tinted (as viewed edgewise, for example W-2, fig. 2) samples of common window glass, which would serve the purpose just as well, at a considerable saving in cost.

\section{SOME DETERMINATIONS OF THE ULTRA-VIOLET SOLAR RADIATION SHUT OUT BY COMMON WINDOW GLASS}

Much of the discussion of the need of special window glasses for transmitting the 302-range of wave lengths of ultra-violet solar radiation is based upon the observation that common window glass shuts out these rays, which have the property of preventing rickets (49). Hence, in connection with the present investigation of the optical properties of the newly developed window glasses for transmitting

$73113^{\circ}-29-2$ 
the 302-range of wave lengths of ultra-violet solar radiation the question arose as to the total amount of these rays, of wave lengths less than about $310 \mathrm{~m} \mu$, that is absorbed by common window glass. This information will be useful in obtaining an estimate of the threshold value of ultra-violet radiation that will be effective for therapeutic purposes. It will be useful also in connection with the specification of the unit of dosage in heliotherapy, discussed in a previous paper (9).

It has been suggested that the unit of dosage be called the "Finsen," in honor of the pioneer in ultra-violet light therapy. The energy value of the unit of dosage may be any convenient, arbitrarily assigned number. Hence, if we define the Finsen Unit as having an intensity (radiant flux density) of $0.001 \mathrm{~g} \mathrm{cal} . / \mathrm{cm}^{2} / \mathrm{min}$., whether of ultra-violet or infra-red radiation, then $1 \mathrm{~F} . \mathrm{U} .=0.001 \mathrm{~g} \mathrm{cal} . / \mathrm{cm}^{2} / \mathrm{min}$.1 millicalory $/ \mathrm{cm}^{2}$ per minute. The most convenient number in ergs is $1,000 \mathrm{ergs} / \mathrm{cm}^{2}$ per second.

The problem of the physiologist is to determine how many units are needed for a single dose. The problem of the physicist is to determine the intensity (the radiant flux density) of the so-called vitalizing or biologically active rays in a given source of ultra-violet radiation, whether the sun, or at a standard distance from an artificial source; also to devise instruments and methods for measuring the radiation stimulus to be used in phototherapy.

The use of such a unit will be simple. For example, suppose that the physicist finds that the ultra-violet solar intensity $=4 \mathrm{~F}$. U. and the physiologist finds that $20 \mathrm{~F}$. U. are required to produce an erythema. Then it will require an exposure of $(20 \div 4=) 5$ minutes in order to produce the desired result.

The problem of accurately determining the amount of ultra-violet solar radiation, in the 302-range of wave lengths, shut out by common window glass, and thus obtaining a measure of the amount involved in therapeutic work, is extremely difficult because the magnitude involved is only a few thousandths of the total incident solar radiation. Hence, owing to atmospheric conditions, it is practically impossible to obtain reliable measurements at sea-level stations except at rare intervals, on perfectly clear days, when for short periods (of 5 to 15 minutes) measurements can be repeated to 0.3 to 0.5 per cent. The average of a large number (20 to 30 ) of such observations appears to be sufficiently precise to obtain an estimate of the amount of short wave length ultra-violet solar radiation shut out by common window glass.

Our measurements were made with direct sunlight as a source, during the noon hours of especially clear days from April to December, 1927 , and early in the year, 1929. On these days we were in telephone communication with I. F. Hand, of the United States Weather Bureau, who gave us the solar radiation intensities, $Q$ at the time of 
our observations. On clear days, for air mass $m=1$, the solar intensity at Washington ranges from $Q=1.23$ to $1.4 \mathrm{~g}$ cal. $/ \mathrm{cm}^{2} / \mathrm{min}$.

Owing to the great variability in the transparency of common window glasses in the ultra-violet, and to the fact that the decrease in spectral transmission is not sharply defined, the spectral range and the total amount of ultra-violet absorbed varies greatly from sample to sample. Hence, after an examination of a large number of samples, we selected a sample (W-10, fig. 2) which represents about the average that is found in the market. This sample is practically opaque at $310 \mathrm{~m} \mu($ tr. $=0.3$ per cent at $313 \mathrm{~m} \mu)$ and transmits about 8 per cent at $320 \mathrm{~m} \mu$.

In the present paper the magnitude of the short wave length ultraviolet component of solar radiation which is shut out by common window glass is derived by several methods which will now be discussed.

Method I.-By calculation from the solar spectral energy curve. In this method the intensities (the relative energies) at different wave lengths are multiplied by the corresponding spectral transmission of the window glass and the areas under the two curves are integrated. The main difficulty lies in determining the solar spectral energy distribution, especially in the extreme ultra-violet. The published data are taken from a smooth spectral energy curve, whereas the bolometrically observed spectral energy curve is deeply indented. Furthermore, the few determinations extant of the ultra-violet spectral energy distribution of the sun differ greatly, depending upon the method of observation. For example, the results obtained by Fabry and Buisson (53) by a photographic comparison of the spectrum of the sun with that of the crater of a carbon arc differ greatly from their earlier photographic measurements (54). In turn all of these data differ greatly from the spectrobolometric measurements obtained by Abbot and Fowle, which are much higher at $300 \mathrm{~m} \mu$. Hence, for the purpose of the present calculations the most reliable spectrobolometric data of Fabry and Buisson are combined with those of Abbot and Fowle (summarized in the Smithsonian Physical Tables, Fowle, 7 th rev. ed.) forming a curve which terminates (10) practically at about $295 \mathrm{~m} \mu$, which is in agreement with other observations for sea-level stations. For Washington (practically sea level) the intensities of the solar radiation of wave lengths 295 to $450 \mathrm{~m} \mu$ is $0.13 \mathrm{~g}$ cal., or 10 per cent of the total incident radiation of all wave lengths, for air mass $m=1$. The solar spectral energy curve at Washington for air mass, $m=1$, coincides practically with the energy curve at Mount Wilson for $m=2$.

By multiplying the solar spectral radiation intensities by the spectral transmission of the window glass, at the different wave lengths as already mentioned, it is found that for the purposes of the 
present calculation the glass becomes practically opaque to wave lengths at about $320 \mathrm{~m} \mu$. The area of the curve extending from 295 to $320 \mathrm{~m} \mu$ (that is, the ultra-violet component between these two wave lengths) relative to the area from 295 to $450 \mathrm{~m} \mu$ is 0.012 (1.2 per cent); and since the area between the wave lengths 295 io 450 $\mathrm{m} \mu$ is 10 per cent of all wave lengths (see preceding paragraph) the ultra-violet component between 295 and $320 \mathrm{~m} \mu$ is 0.12 per cent ( $=0.15$ per cent if we use only the Smithsonian data) of the total incident solar radiation.

On this same basis, the ultra-violet component between 295 and $310 \mathrm{~m} \mu$ (which is one-third the area between 295 and $320 \mathrm{~m} \mu$ ) is 0.04 per cent ( 0.05 per cent if we use only the Smithsonian data) of the total incident solar radiation at sea level, or about $0.0005 \mathrm{~g} \mathrm{cal} . / \mathrm{cm}^{2} / \mathrm{min}$. Pettit (47) has recently calculated a value of about $0.001 \mathrm{~g} \mathrm{cal.} / \mathrm{cm}^{2} /$ min.

Method II.-By direct measurements of wide spectral bands of solar radiation using a spectropyrheliometer (11) in which the total solar radiation of wave lengths extending from 300 to $389 \mathrm{~m} \mu$, on the clearest days, was about 2.2 per cent of the total incident radiation $(Q=1.35 \mathrm{~g}$ cal. on September 25,1919). The calculated value on the above-described spectral energy curve is 3.0 per cent of the total, which is in good agreement with the observed value of 2.2 per cent.

Using this spectropyrheliometer, the ultra-violet component of solar radiation of wave lengths less than $300 \mathrm{~m} \mu$ was found to be less than 2 per cent of the radiation between 300 to $389 \mathrm{~m} \mu$ or less than $(0.022 \times 0.02=) 0.00044$ of the total incident solar radiation (September 24, 1919, $Q=1.31 \mathrm{~g}$ cal.). On this basis the ultra-violet of wave lengths of less than $310 \mathrm{~m} \mu$ would be about three times this value or about 0.0012 (0.12 per cent) of the total incident solar radiation.

Method III.-By isolating the ultra-violet component from the total incident solar radiation (of wave lengths less than $1,400 \mathrm{~m} \mu$ ) by using the standard sample of window glass as a screen. This method was used in measuring the spectral component radiation from stars (12) and from artificial sources (13) of radiation.

This method of observation consisted in exposing a copper-constantan thermocouple (covered with a cell of water $1 \mathrm{~cm}$ in thickness, with windows of quartz, to eliminate the infra-red of wave lengths longer than $1,400 \mathrm{~m} \mu$ ) to the sun and noting the decreases in the galvanometer deflections when increasing amounts of the ultraviolet were shut out $(a)$ by one sample then $(b)$ by two samples of the same kind of glass. The combination of two samples was used in order to obtain a correction factor for the ultra-violet rays of wave lengths longer than about $310 \mathrm{~m} \mu$, partly absorbed by this sample of window glass. 
For example, when using quartz or Corex-A glass, which have practically no absorption in the ultra-violet of wave lengths longer than $295 \mathrm{~m} \mu$, the second sample transmitted 91.8 per cent of the total solar radiation (of wave lengths less than $1,400 \mathrm{~m} \mu$ which is the long wave-length limit of the water cell) which had passed through the first sample. This is in agreement with the value calculated from reflection data. From similar observations on the sample W-4 (and of W-10, fig. 2) of common window glass which was used as a standard (14), it was found that the second sample transmitted 85.3 to 85.7 per cent (average 85.5 per cent during the season) of the solar radiation that had passed the first sample. The value calculated from the above-mentioned solar spectral energy transmitted through the water cell is 85.4 per cent.

As shown in Figure 2, (W-4) sample No. 4, of common window glass becomes practically opaque at about $310 \mathrm{~m} \mu$. Hence, the transmission factor 85.5 per cent may be used to correct for the solar radiation, of wave lengths 310 to $1,400 \mathrm{~m} \mu$, absorbed and reflected by the glass screen, and thus obtain the amount of ultra-violet, principally of wave lengths shorter than about $310 \mathrm{~m} \mu$, which is absorbed by this glass.

Measurements of this type gave values of ultra-violet solar radiation, shut out by common window glass, ranging from 1.5 per cent (15) of the total incident radiation of all wave lengths in May and June when the air mass was $m=1$, to 0.8 or 0.9 per cent in December when the air mass was $m=2$. Evidently this sample of window glass shut out ultra-violet of longer wave lengths than those having a therapeutic value. For, as just mentioned, ultra-violet radiation of wave lengths 297 to $302 \mathrm{~m} \mu$ are claimed to be the most potent in preventing rickets; also that during the winter (air mass larger than $m=2$ ) these wave lengths are almost completely absorbed by the atmosphere. Hence, in the wintertime the amount of ultra-violet, of wave lengths 297 to $302 \mathrm{~m} \mu$, shut out by this sample of glass should have been 0 per cent instead of 0.8 to 0.9 per cent of the total incident radiation. From this it appears that the above-mentioned correction for absorption by window glass is probably too low when considered in terms of biological activity and that, in the latitude of Washington $\left(38.9^{\circ}\right)$, during the noon hours of the clearest days in May and June (airmass $m=1$ ) the amount of activating radiation in the 302-region of sunlight, shut out by common window glass, is the difference between the values observed in the summer and in the winter. This is of the order of $(1.5-0.9=) 0.6$ per cent of the total incident solar radiation, or about $0.007 \mathrm{~g} \mathrm{cal} . / \mathrm{cm}^{2} / \mathrm{min}$. This, of course, would represent the upper limit on the clearest days which are few in number. The socalled average value would be much less, say, $0.001 \mathrm{~g} \mathrm{cal} . / \mathrm{cm}^{2} / \mathrm{min}$., and more likely even lower than this value. 
While it has recently been shown biologically that, during the winter months in Washington, solar radiation contains some short wave length ultra-violet radiation that is beneficial in preventing rickets, it is evident that, of the above-mentioned 0.9 per cent, the greatest part is of wave lengths at about $313 \mathrm{~m} \mu$, which are the least active, and that only a small part of this 0.9 per cent consists of wave lengths at $302 \mathrm{~m} \mu$ which are the most active in preventing rickets.

This value of 0.9 per cent for an air mass, $m=2$, is substantiated by measurements made in the early forenoon, in summer. Hence, the above value, 0.6 per cent, as obtained by this method, is probably a fair estimate of the amount of the most potent of the activating rays in ultra-violet solar radiation shut out by common window glass.

Method IV.-By isolating the ultra-violet part of the solar spectrum by means of a screen and determining the amount of this shut out by common window glass. For a filter we used a plate of ultra-violet transmitting glass, Corning $G 986 \mathrm{~A}$ which, for a thickness of $3 \mathrm{~mm}$, has a transparent band, $A$, at 250 to $440 \mathrm{~m} \mu$ with a high transmission (about 85 per cent) of the incident short wave length ultra-violet solar rays at 295 to $350 \mathrm{~m} \mu$. Unfortunately it does not completely absorb all of the infra-red rays. (Fig. 10.) However, when used in conjunction with the screen of water (cell $1 \mathrm{~cm}$ thickness) the total infra-red solar radiation of wave lengths extending from 600 to 1,400 $\mathrm{m} \mu$ (band $B$ ) as determined experimentally by isolating this region with a screen of Schott's (16) red glass (No. 4512) is only about three times that of the ultra-violet band, $A$, at 295 to $440 \mathrm{~m} \mu$ in summer and about four times this amount in winter.

From two closely agreeing measurements (Apr. 27 and May 2, 1927 ) it was found that this combination filter consisting of a water cell and a certain sample of Corning glass, G986A, transmitted 8.37 per cent of the total incident radiation. Of this amount about 30 per cent (or about 2.5 per cent of the total) was located in the ultraviolet band transmitted by this glass screen. This is in good agreement with the calculated value of 2.3 per cent of the total incident radiation in the band $A$ (295 to $440 \mathrm{~m} \mu$ ).

From this it will be noticed that this method has a distinct advantage over the preceding method in that the ultra-violet component shut out by window glass is greatly magnified relative to the total radiation measured-amounting to 5 per cent, or more, of the total as compared with 1.5 per cent of the total by the preceding method.

By isolating the infra-red band $B(\lambda 600$ to $1,400 \mathrm{~m} \mu)$ by temporarily inserting a sample of Schott's red glass, it was found that our standard sample of common window glass transmitted 82 per cent of the incident radiation for air mass $m=2.4$ (January 7 and 8 , 1929). This is in as good agreement with the calculated value (80.5 per cent) as can be expected in view of the fact that the latter is 
based upon a smooth solar spectral energy curve, whereas the energy distribution in this part of the spectrum is deeply indented by absorption bands of (atmospheric) water vapor.

A further test of the reliability of this method was obtained (on January 7 and 8,1929$)$ by observing the transmission of our standard sample of window glass for both bands of radiation $A$ and $B$ (tr. $=79.6$ per cent) and for the infra-red band $B$, (tr. $=82$ per cent) from which, by taking into consideration that the observed intensity of $B$ is about four times $A$, it follows that this sample transmitted 70 per cent of the ultra-violet in the band, $A$, at 295 to $440 \mathrm{~m} \mu$. This is in as good agreement with the calculated value (68 to 69.5 per cent) as can be expected in view of the uncertainty of the spectral energy distribution of the sun in the region of 295 to $310 \mathrm{~m} \mu$, especially when the altitude of the sun is low, air mass $m=2.4$.

By making measurements (a) with one piece of our standard of window glass and $(b)$ with two pieces of this window glass interposed (see Method III) it was found that at the noon hour on June 8, 1927 (sky hazy, $Q=0.9 \mathrm{~g}$ cal.), the amount of short wave length (less than about $310 \mathrm{~m} \mu$ ) ultra-violet rays shut out by common window glass was 3.2 per cent of the radiation transmitted through this filter or $(0.032 \times 0.0837=) 0.27$ per cent of the total incident solar radiation.

This is in good agreement with the value obtained by calibrating the galvanometer deflection by exposing the thermopile to a standard of radiation and then noting the deflection corresponding to the amount of short wave length ultra-violet solar radiation shut out by our sample of window glass. Since the thermopile intercepted radiation from about $35^{\circ}$ of the sky, which contains relatively more of the short wave length ultra-violet rays than direct sunlight, the amount of ultra-violet radiation shut out by common window glass, as determined by Methods III and IV, is slightly higher than would be obtained by not including part of the sky in the solar radiation measurement. In practice, however, the patient would be exposed to the sky as well as the sun, and, since these values are upper limits anyway, it would be illusory to attempt refinements in the measurements.

On two very clear days (June 27 and 29, 1927) the amount of short wave length ultra-violet rays shut out by common window glass was about 6 per cent of the radiation transmitted by the filter, or 0.48 and 0.50 per cent (air mass $m=1$; intensity $Q=1.4$ and $1.3 \mathrm{~g}$ cal.), respectively, of the total incident solar radiation.

On two clear days in the winter, at the noon hour, when the air mass was $m=2.4$, the amount of ultra-violet shut out by our sample of common window glass was 0.07 and 0.096 per cent, respectively. (Fig. 1.) It is relevant to cite the following data: January 7, 1929; dust low; fleeting clouds; $Q=1.14 \mathrm{~g}$ cal.; conditions somewhat below 
the average. January 8, 1929; clear cold, $Q=1.33 \mathrm{~g}$ cal.; March 7, high winds, fewest dust particles for two years; $Q=1.398 \mathrm{~g}$ cal. at $12 \mathrm{~m}$; atmospheric conditions somewhat above the average for January and March.

It is interesting to note that this screen method is very sensitive to small variations in intensity of the short wave length ultra-violet solar radiation which enabled us to record rapid changes in the transparency of the atmosphere, as for example on March 8, 1929. (Fig. 1.)

Assuming, as in the preceding method, that this sample of window glass shuts out ultra-violet solar radiation of longer wave lengths than are effective for therapeutic purposes, then the difference between the observed summer and winter values represents more nearly

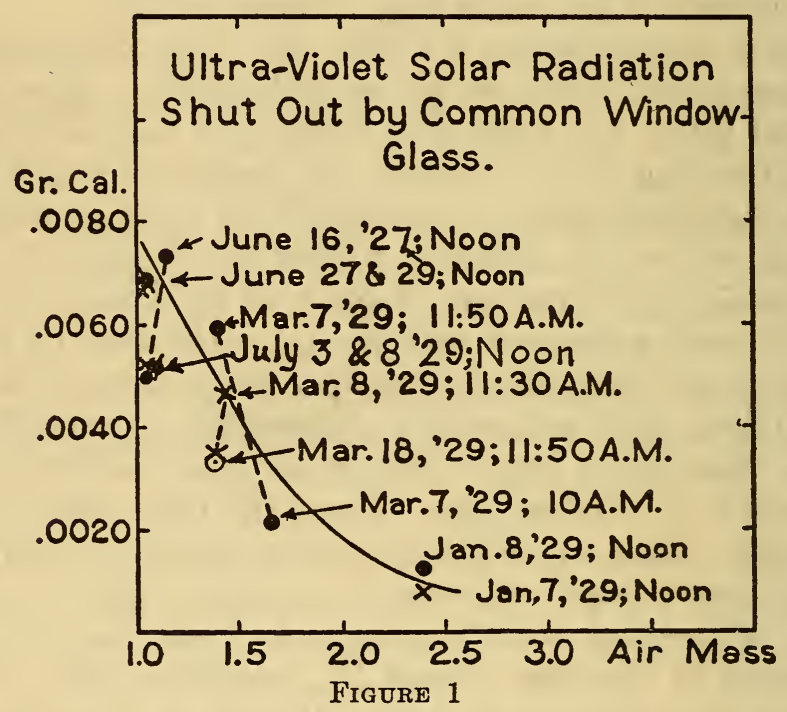

the magnitude of the most potent ultra-violet rays available in sunlight at the noon hours on the clearest days in summer. This amounts to about 0.4 per cent of the total incident radiation or about $0.005 \mathrm{~g} \mathrm{cal} . / \mathrm{cm}^{2} / \mathrm{min}$., and is easily reduced to a much smaller value by dust and smoke.

As already mentioned, recent biological tests made by Fleming (51) by exposing rats to the sun in Washington, and by Russell and Massengale (52) by exposing chicks to the sun, in New Brunswick, N. J. (lat. $40.5^{\circ} \mathrm{N}$.), show that during the winter months of January, February, and March there is sufficient ultra-violet radiation present in sunlight to produce an antirachitic effect. Hence, at least part of the above-observed values of 0.07 to 0.09 per cent, no doubt, includes ultra-violet wave lengths having an antirachitic action. However, it 
does not modify our conclusions, whether or not we deduct this value from our data observed (for air mass $m=1$ ) in the summer time.

In Method III, the amount of ultra-violet shut out by the window glass was about 1 to 2 per cent of the amount transmitted by the water cell, which transmitted about 75 percent of the total incident radiation.

In Method IV, the amount of ultra-violet shut out was about 6 per cent of the total measured, which latter, however, was only about 8.4 per cent of the total incident solar radiation. As a result, a higher sensitivity was required and there was a much greater fluctuation in the single readings. Hence, this method was used only on a few days when the sky appeared free from clouds of water vapor (as viewed through Noviweld glasses) and there was no strong wind. However, the disturbances by the wind could be remedied by using a vacuum thermopile. In spite of the greater fluctuation in the individual readings, it is the opinion of the writers that the data obtained by Method IV are the most reliable. Hence, even though it may not be possible to find a means for eliminating the infra-red rays between 600 and $1,400 \mathrm{~m} \mu$, this screen method appears promising as an approximate method for isolating the ultra-violet radiation of wave lengths less than $310 \mathrm{~m} \mu$. For this purpose two sheets of optical glass ${ }^{2}$ (practically free from iron and hence free from the absorption band at $1,000 \mathrm{~m} \mu$ ) should be used instead of the samples of common window glass used in the present investigation, in which the information desired was for another purpose.

It is to be emphasized that high accuracy can not be expected. However, in the absence of any quantitative data, of this type, at least a beginning has been made. The exact value of the amount of ultra-violet shut out depends greatly upon the sample of window glass selected. For example, the sample of window glass, W-2 (fig. 2) which was exceptionally transparent (tr. $=3.4$ per cent at $313 \mathrm{~m}_{\mu}$ ) shut out only 0.28 per cent of the total or $0.003 \mathrm{~g}$ cal.) of the short wave length ultra-violet as compared with the standard, W-10 (tr. $=0.3$ per cent at $313 \mathrm{~m} \mu$ ) which on the same day, shut out 0.48 per cent of the total, or $0.0053 \mathrm{~g} \mathrm{cal} . / \mathrm{cm}^{2} / \mathrm{min}$. This, however, was an exceptional sample whereas the object is to provide data on the so-called average window glass. In connection with these measurements, reference may be made to the estimates recently published by Doctor Clark (48) who used the rate of blackening of zinc sulphide as a method of measuring ultra-violet radiation, and recorded a variation in intensity of solar radiation, between 290 and $310 \mathrm{~m} \mu$, which ranged from about 500 ergs in winter to about 4,000 ergs in summer, in Baltimore. This is in good agreement with our values which range from 600 ergs in winter to 5,000 ergs in summer.

\footnotetext{
2A barium flint glass (nd 1.605) made at the Bureau of Standards has recently been found satisfactory for this purpose.
} 
TABLE 1.-Summary of estimates of the ultra-violet component radiation between the wave lengths 295 and $\$ 10 \mathrm{m \mu}$ relative to the total incident solar radiation of all wave lengths, at sea level, at Washington, D. C., air mass $m=1$

\begin{tabular}{|c|c|c|}
\hline & How obtained & Per cent \\
\hline Method I. & By calculation from the solar spectral energy curve.. & 0.04 \\
\hline Method II & By using the spectropyrheliometer data of Coblentz and Kahler (9) & .12 \\
\hline Method III... & By isolating the short wave length ultra-violet component by means of a sample & .60 \\
\hline Method IV... & $\begin{array}{l}\text { By isolating the ultra-violet part of the solar spectrum by means of a filter of } \\
\text { Corning G986A glass and determining the amount shut out by common } \\
\text { window glass. }\end{array}$ & .40 \\
\hline (1) & Mean & 3 \\
\hline
\end{tabular}

A comparison of these four methods of determining the amount of short wave length ultra-violet solar radiation shut out by common window glass shows that the values obtained by direct measurement ( 0.4 per cent) are about three to sixteen times larger than the values calculated from the probable spectral energy distribution which is admittedly in doubt for sea-level stations.

The values obtained by these difierent methods are so discordant that the conclusion to be drawn is that even on the clearest days at the noon hour, in summer, the total amount of ultra-violet solar radiation of wave lengths less than $310 \mathrm{~m} \mu$, which has a therapeutic effect in preventing rickets, is extremely small, at the most amounting to only about 0.3 per cent of the total incident solar radiation (or about $0.004 \mathrm{~g}$ cal.) and more likely only one-tenth of this value at sea-level stations. The value on cloudy days, at sunrise and at sunset, and in high latitudes would be very much smaller.

In conclusion, it is to be emphasized that the amount of ultra-violet shut out by common window glass will depend upon the sample examined. We have selected what appeared to be an average sample, and have found that it shuts out short wave length ultraviolet radiation amounting to about 0.4 per cent of the total incident solar radiation. But this sample may have shut out ultra-violet of a greater range of wave lengths than is efiective for therapeutic purposes. As already noted a more transparent sample would shut out short wave length ultra-violet amounting to less than the aboveestimated value of 0.4 per cent of the total incident radiation and yet might not show any difference in a therapeutic efficiency test.

As already mentioned, all this interest in special window glasses is based upon the observation that common window glass shuts out ultra-violet rays having a therapeutic value, especially in preventing rickets (23). In this connection it is relevant to cite recent tests by Bethke and Kennard (49) made at Wooster, Ohio (lat. $40^{\circ} 45^{\prime} \mathrm{N}$.; altitude about 800 feet), between March 18 and May 27, 1926. These experiments covered the period between the first and tenth week of the life of the chick. The season was already sufficiently 
advanced to insure the presence of an appreciable amount of ultraviolet vitalizing rays. The chicks that were exposed to direct sunlight, or sunlight filtered through a glass substitute that transmitted an appreciable amount of the vitalizing rays, did not develop rickets, whereas those that were exposed to the solar rays filtered through common window glass developed rickets.

It should be emphasized that these measurements of the amount of ultra-violet light shut out by window glass were made only on the clearest days which, at sea-level stations, are few in number. Hence, the numerical values represent the approximate upper limit that may be expected. The so-called average value, which would be much lower, will depend upon the condition of the sun (sun spots) the altitude and the latitude of the station and the almost infinite variety of air pollution and weather conditions that are encountered at different seasons of the year and during different years.

The whole discussion indicates the importance of having an artificial source of ultra-violet radiation (and a unit of dosage that is correlated with ultra-violet similar to solar radiation) that can be controlled, which is not possible with solar radiation.

\section{EFFECT OF SOLARIZATION UPON THE ULTRA-VIOLET TRANSMISSION OF WINDOW GLASSES}

In view of the fact that improvements may be expected in the transmissive properties of all of these glasses, it is to be emphasized that the present data on Helioglass and Vitaglass are based upon an examination of melts that were marketed prior to February 1, 1929.

Under this caption data are given on the transmissive properties of window glasses in the ultra-violet, visible and infra-red spectrum, and particularly on the decrease in transmission of ultra-violet radiation through these glasses as the result of photochemical stabilization by exposure to artificial sources of radiation and to the sun. A comparison of the ultra-violet transmission of various glasses, after solarization, is illustrated in Figure 15.

In Figure 2 is shown the ultra-violet spectral transmission of various window glasses when new. From this illustration it appears that, as regards their spectral transmissions, these glasses fall into three distinct groups: (a) Quartzlite and common window glass which transmit litțle or no ultra-violet in the region of 297 to $310 \mathrm{~m} \mu$; (b) Vitaglass, Helioglass, and Holviglass which transmit considerable radiation at $302 \mathrm{~m} \mu$; and (c) Corex-D, and quartz glass which transmit over 85 per cent at $302 \mathrm{~m} \mu$ (for "single strength" glass, thickness = 0.09 inch $=2.3 \mathrm{~mm}$. B. S. Circular No. 164).

By means of these spectral transmission curves an estimate of the relative transmissions of these various glasses, for the ultra-violet rays which are shut out by common window glass, may be obtained 
by reading from the curves the values of the transmission at $302 \mathrm{~m} \mu-$ the wave length of an intense mercury line, of convenient value for

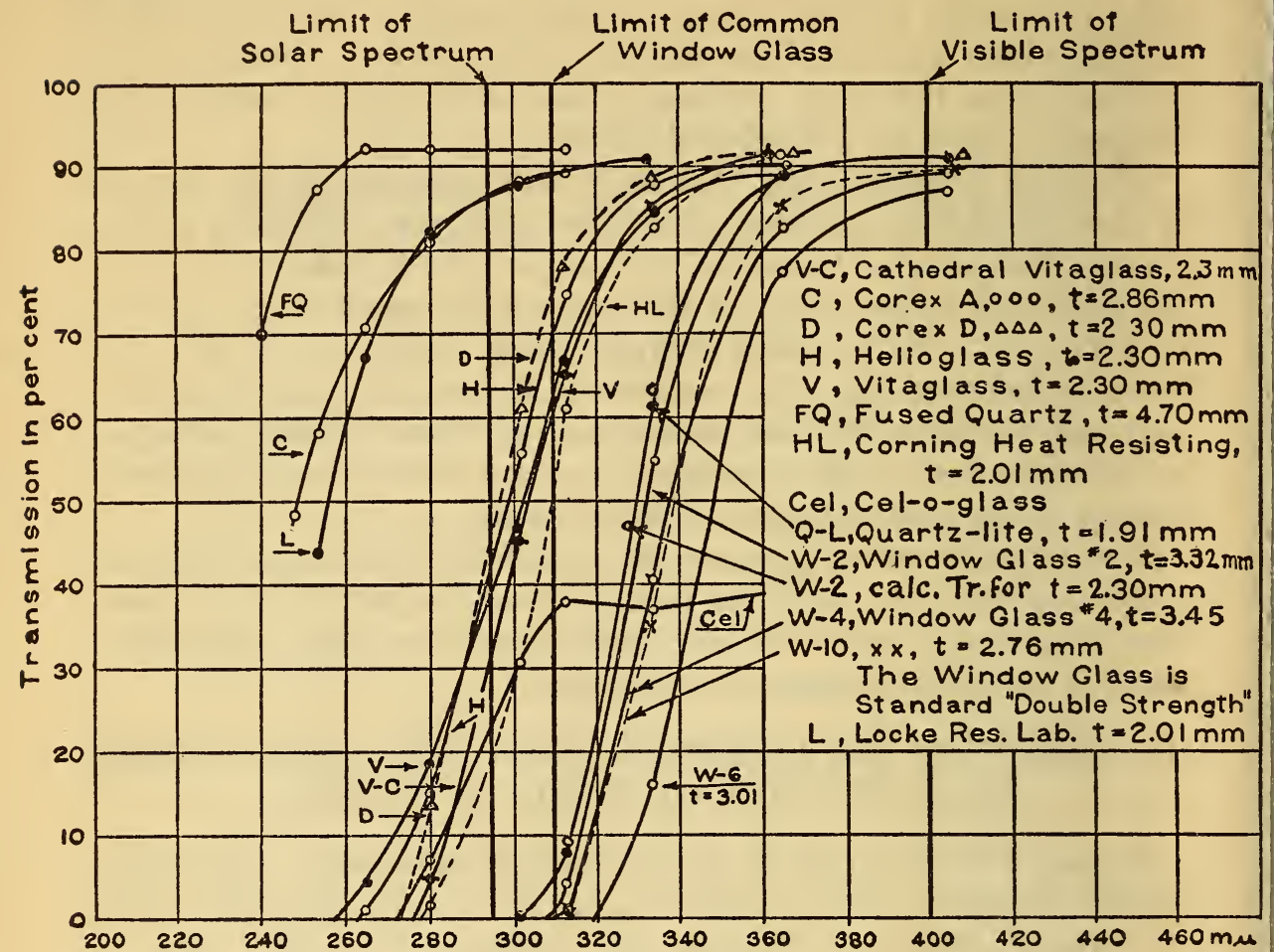

FIGURE 2.-Ultra-violet spectral transmission of various window glasses when new

making such tests. Table 2 gives the average transmission values (37) for this wave length.

TABLE 2.-Transmission of various glasses at $302 \mathrm{~m} \mu$, when new and after photochemical stabilization by exposure at a distance of $15 \mathrm{~cm}$ from a quartz mercury arc for 10 hours

\begin{tabular}{|c|c|c|c|c|}
\hline \multirow{2}{*}{ Trade name } & \multirow{2}{*}{$\begin{array}{l}\text { Number } \\
\text { of } \\
\text { samples } \\
\text { tested }\end{array}$} & \multirow{2}{*}{$\begin{array}{l}\text { Average } \\
\text { thickness }\end{array}$} & \multicolumn{2}{|c|}{$\begin{array}{l}\text { Average transmis- } \\
\text { sion }\end{array}$} \\
\hline & & & New & $\begin{array}{c}\text { After } \\
\text { exposure }\end{array}$ \\
\hline $\begin{array}{l}\text { Quartz glass } \\
\text { Corex-D } \\
\text { Neuglas. } \\
\text { Uviol-Jena } \\
\text { Helioglass (Vioray) }\end{array}$ & $\begin{array}{r}1 \\
15 \\
12 \\
14 \\
24\end{array}$ & $\begin{array}{r}m m \\
4.7 \\
2.3 \\
2.3 \\
2.3 \\
2.3 \\
2.3\end{array}$ & $\begin{array}{c}\text { Per cent } \\
92 \\
61 \\
63 \\
58 \\
58\end{array}$ & $\begin{array}{c}\text { Per cent } \\
92 \\
59 \\
49 \\
43 \\
40\end{array}$ \\
\hline $\begin{array}{l}\text { Sunlit ultra-violet health glass. } \\
\text { Vitaglass. } \\
\text { Cel-o-glass } \\
\text { Quartzlite. } \\
\text { Common window glass. }\end{array}$ & $\begin{array}{r}9 \\
19 \\
5 \\
16 \\
14\end{array}$ & $\begin{array}{l}2.3 \\
2.3 \\
3.1 \\
1.9 \\
3.3\end{array}$ & $\begin{array}{l}65 \\
48 \\
30 \\
0 \\
0\end{array}$ & $\begin{array}{l}39 \\
23 \\
0\end{array}$ \\
\hline
\end{tabular}

1 Vioray is the foreign trade name of Helioglass.

This consists of a fine wire screen whose interstices are covered with cellulose acetate. The value of 30 per cent includes practically all the rays diffusely transmitted.

About.

- About 0.2 per cent for $t=2.3 \mathrm{~mm}$. 
'I'he foregoing data are completely verified numerically in a recent paper by Goodman and Anderson (38) who placed Quartzlite in Class I with window glass which, according to their observations had no measurable transmission for ultra-violet radiation of wave lengths 293 to $310 \mathrm{~m} \mu$, while Helioglass (Vioray) and Vitaglass are placed in Class II with a transmission of 56 and 48 per cent, respectively.

Unfortunately, as stated elsewhere in this paper, in most of these glasses the long wave length side of the ultra-violet absorption band coincides closely with the spectral region of activating rays, at 297 to $302 \mathrm{~m} \mu$, and, hence, a slight variation in thickness produces a great change in transmission of these rays; for example, for glasses having a transmission of 40 to 50 per cent (at, say, $302 \mathrm{~m} \mu, t=2.3 \mathrm{~mm}$ ) a varia-

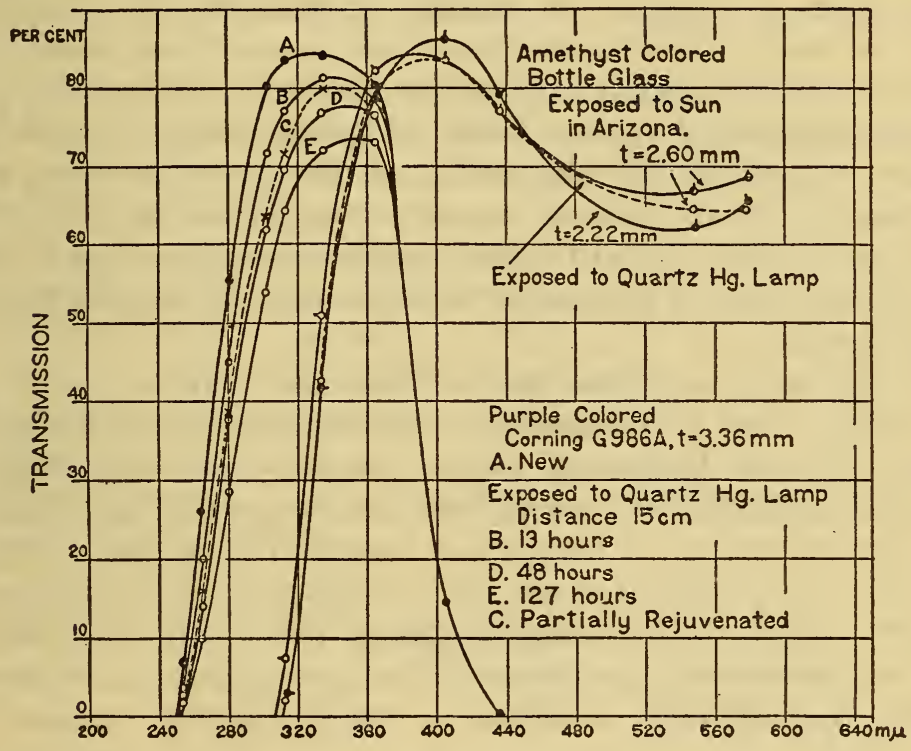

Figure 3

tion in thickness of $0.1 \mathrm{~mm}$ produces a change in transmission of 1.2 per cent. Since these glasses are handblown, a variation of $0.5 \mathrm{~mm}$ (or 6 per cent in transmission) is frequently found in a single sheet of window glass.

As is well known, certain kinds of glass (for example, bottle glass, fig. 3) containing iron as an impurity, which have been decolorized by means of selenium or manganese, undergo a photochemical change and exhibit an amethyst color when exposed to solar radiation, especially after exposure to the intense sunshine in the desert regions of our Western States.

A further illustration is the familiar amethyst color developed in glass globes which inclose carbon ares used in street lighting. Evidently the material which produces this discoloration is variable in its 
chemical stability under the action of light. For example, we bave observed an occasional gas lamp, containing a Welsbach mantle, in which the larger outer glass inclosure had a conspicuous amethyst color while the small glass chimney, which formed the immediate surrounding of the mantle, showed no color.

\section{METHODS OF PHOTOCHEMICAL STABILIZATION}

Eariy in this investigation it was observed that these special window glasses underwent a photochemical reaction, and decreased in transmission, especially in the short wave length ultra-violet, after exposure to sunlight and to artificial sources emitting ultra-violet radiation. It was then surmised that it would probably require several years of exposure to sunlight in order to photochemically stabilize at least some of these glasses, and a search was instituted for a source of artificial radiation suitable for accelerating this stabilization. Duplicate samples of various makes of special window glasses were, therefore, exposed for different lengths of time to the unfiltered radiation from the quartz mercury vapor arc and from the white flame carbon arc; also a ("Fad-Ometer") carbon arc surrounded with a glass chimney that is opaque to radiation of wave lengths less than about $320 \mathrm{~m} \mu$.

Duplicate samples of glass were exposed also to the sun, at an angle of $45^{\circ}$ facing south in Washington (altitude 50 feet), and through the courtesy of C. O. Lampland, at the Lowell Observatory, Flagstafi, Ariz. (altitude 7,250 feet), where there is a clearer sky, more sunshine and a greater amount of ultra-violet than in Washington. In addition to this, an examination was made of samples taken from hospital windows. Some of these samples showed practically no further decrease in transmission on exposure to the quartz mercury are showing that the photochemical stabilization was practically complete.

\section{EFFECT OF TEMPERATURE UPON THE SOLARIZATION OF WINDOW GLASSES}

The solarization of ultra-violet transmitting window glasses is essentially a problem in photochemistry which is a function $(a)$ of the temperature, $(b)$ of the absorptive properties of the material for ultra-violet radiation, (c) of the presence of a material (for example, ferrous iron (39) as an impurity) which reacts to ultra-violet rays; and $(d)$ the source of radiation.

Solarization is commonly attributed to the presence of iron in the glass. We have found that (soda-lime) glasses, which were prepared under the direction of F. C. Flint, of the Hazel-Atlass Glass Co., from chemically-pure (iron-free) material, in receptacles that could not contaminate the material with iron, do not solarize on exposure to ultra-violet radiation of wave lengths 250 to $350 \mathrm{~m} \mu$ 
which are absorbed by the glass. On the other hand, as will be noticed on a subsequent page, we have found that Corex-A glass, which contains iron as an impurity and is transparent to radiation of wave lengths longer than $302 \mathrm{~m} \mu$ does not solarize on exposure to the sun, but decreases rapidly in transmission on exposure to ultraviolet radiation of wave lengths 250 to $280 \mathrm{~m} \mu$ which are absorbed by this glass.

It is to be expected that the solarization will continue so long as any of the chemically active material remains uncombined. This is evident from the fact that after the glass has practically ceased to decrease in transmission, because the activitating rays can not penetrate the entire layer of glass, the solarization is renewed on turning the under (previously unexposed) side of the glass toward the source of radiation.

In our solarization tests during the summer and fall of 1927 it was found that the transmission of the glasses decreased to a constant value. The following summer these glasses underwent a further decrease in transmission on exposure to the sun. This seemed to be owing to the increased temperature. To test this question duplicate samples of Helioglass and Vitaglass were exposed to the mercury arc, the one at a temperature of about $70^{\circ} \mathrm{C}$. and the other at about $15^{\circ} \mathrm{C}$. As shown in Table 3 the samples at the higher temperature decreased the most in transmission, as is to be expected for a small rise in temperature. As will be noticed on a subsequent page these glasses can be rejuvenated by heating them to a temperature of $200^{\circ} \mathrm{C}$. or higher.

TABLE 3.-Effect of temperature on the solarization of window glasses exposed to the mercury arc

\begin{tabular}{|c|c|c|c|c|}
\hline 4 & Transmission of - & Now & $\begin{array}{c}\text { Exposed } \\
1 \text { hour }\end{array}$ & $\begin{array}{l}\text { Exposed } \\
11 \text { hours }\end{array}$ \\
\hline $\begin{array}{l}\text { Helioglass }(t=1.71 \mathrm{~mm}) \\
\text { Cool } \\
\text { Hot }\end{array}$ & & $\begin{array}{r}\text { Per cent } \\
56.0 \\
56.0\end{array}$ & $\mid \begin{array}{r}\text { Per cent } \\
46.4 \\
43.0\end{array}$ & $\begin{array}{r}\text { Per cent } \\
42.0 \\
38.2\end{array}$ \\
\hline $\begin{array}{l}\text { Vitaglass }(t=2.5 \mathrm{~mm}) \\
\text { Cool_ } \\
\text { Hot_- }\end{array}$ & & $\begin{array}{l}42.5 \\
42.5\end{array}$ & $\begin{array}{l}26.5 \\
24.8\end{array}$ & $\begin{array}{l}20.0 \\
18.3\end{array}$ \\
\hline
\end{tabular}

\section{REJUVENATION OF GLASSES}

As is to be expected, the photochemical action producod by the ultra-violet rays can be reversed by heat treatment. The rate of recovery, of course, depends upon the temperature to which the glass is heated (40). There seems to be no measurable recovery in transmitting power of the solarized glass on standing in the dark, at room temperatures. 
In Figure 6 is shown a series of photochemical aging and rejuvenation curves of Vitaglass in which the process was repeated through several cycles, with no perceptible fatigue or permanent change in chemical composition of the material, which would be evidenced by a change in the transmission curve. Further experiments on rejuvenation are depicted in Figure $11-$ Corex- $A$.

\section{VITAGLASS}

Of the various new glasses now obtainable for therapeutic purposes, Vitaglass has been on the market the longest. Hence, concerning this glass, we have been able to obtain the most information regarding solarization. This glass has been marketed in the smooth and in the "cathedral" finish. Apparently there is a difference in the chemical composition of these two types of glasses. This is apparent from the transmission curves, Figure 2 ( $V=$ smooth finish, and $V-C=$ cathedral surface, polished before examination) and also from the color as viewed edgewise, under which conditions the cathedral finish (at least the kind first marketed) shows but little color, while the smooth finish has a decidedly greenish-yellow tinge and an appreciably lower transmission in the violet. This probably explains the confusing results obtained by various observers.

\section{(a) EFFECT OF SUNLIGHT}

As shown in Figure 2 the transmission of a polished sample of cathedral Vitaglass $(V-C)$ is decidedly lower than the smooth Vitaglass $(V)$ in the region of $280 \mathrm{~m} \mu$ when new. But the chemical constituents of the glass used in the cathedral finish seem to be less affected by sunlight. For example, the dotted curves in Figure 4 show the transmission of a (polished) sample of cathedral-finish Vitaglass ( $V-C$ in fig. 2 ; thickness $2.3 \mathrm{~mm}$ ) that had been in use for two years in an animal house. The upper dotted curve gives the transmission at the edge of the glass which had been covered with putty, and, hence, not exposed directly to light.

The transmission of ultra-violet of wave lengths 290 to $310 \mathrm{~m} \mu$ through this unpolished sample (which was very soiled when received) was only 22 per cent before washing and 58 per cent after washing, an increase of 36 per cent, showing the importance of keeping the windows clean in order to maintain a high transmission.

A further exposure of this (polished) sample of cathedral Vitaglass (fig. 4) to the sun, in Washington from March 7 to May 7, 1928 (about nine weeks) decreased the transmission at $302 \mathrm{~m} \mu$ by less than 1 per cent. An additional exposure of 10 hours to the quartz mercury arc changed the transmission at $302 \mathrm{~m} \mu$ from 42 per cent (fig. 4) to 36 per cent, showing that solarization was about complete before exposure to the mercury arc. 
On the other hand, a sample of the smooth finished Vitaglass (tinged bluish white as viewed edgewise) which had been in a hospital window in Rhode Island for a year, was found to have a transmission of only 25 per cent at $302 \mathrm{~m} \mu$ (for thickness, $t=2.3 \mathrm{~mm}$ ). Further exposure to the quartz mercury arc reduced the transmission but little, showing that solarization was practically complete.

In the present investigation, the samples of glass were exposed continuously, day and night, at an angle of $45^{\circ}$ facing south. Our tests show that the greatest decrease in the transmission of the greenish-yellow tinged (as viewed edgewise) Vitaglass occurs during the first two or three weeks of exposure to direct sunlight. This is illustrated by the full line curves in Figure 4, which show the de-

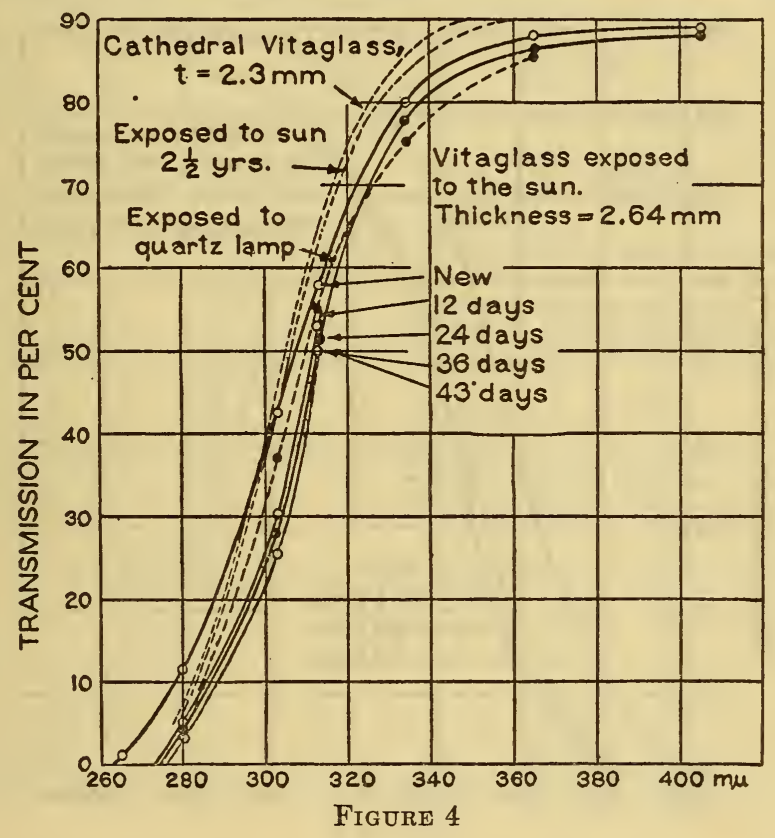

crease in transmission of a sample of greenish-yellow tinged Vitaglass that was exposed to the sun, in Washington, during the months of August and September, 1927. Fortunately, this occurred at a time when there was but little cloudy weather, the first 24 days being practically cloudless. The greatest decrease in transmission occurred during the first 12 days of exposure. After an exposure of 36 to 43 days the transmission of this sample did not decrease perceptibly. This is a typical example of the change in transmission that occurs in Vitaglass as a result of solarization. In the upper part of Figure 6 is depicted the decrease in transmission of this sample of glass at $302 \mathrm{~m} \mu$ which shows that the greatest change in transmission occurs during the first few weeks' exposure to the sun.

$73113^{\circ}-29-3$ 
The transmission of Vitaglass after solarization by exposure to the sun is about 25 per cent at $302 \mathrm{~m} \mu$, although an occasional sample is found that transmits 35 per cent while others transmit only 17 per cent after seven months' exposure to the sun, showing the great variation in purity that occurs in different melts. These data are summarized in Tables 4, 5, 6, and 7, and illustrated in Figure 15.

In another test, a sample of Vitaglass $(t=2.35 \mathrm{~mm})$ was exposed directly to the sun, between 9 a. $\mathrm{m}$. and $3 \mathrm{p}$. m. for a total of 123 hours, during the months of June, July, and August, 1927, which decreased the transmission from 47 to 32 per cent at $302 \mathrm{~m} \mu$. (Fig. 6.)

Even the weak intensity of the light from the north sky in winter decreases the transmission of Vitaglass. A sample $(t=2.6 \mathrm{~mm})$ that

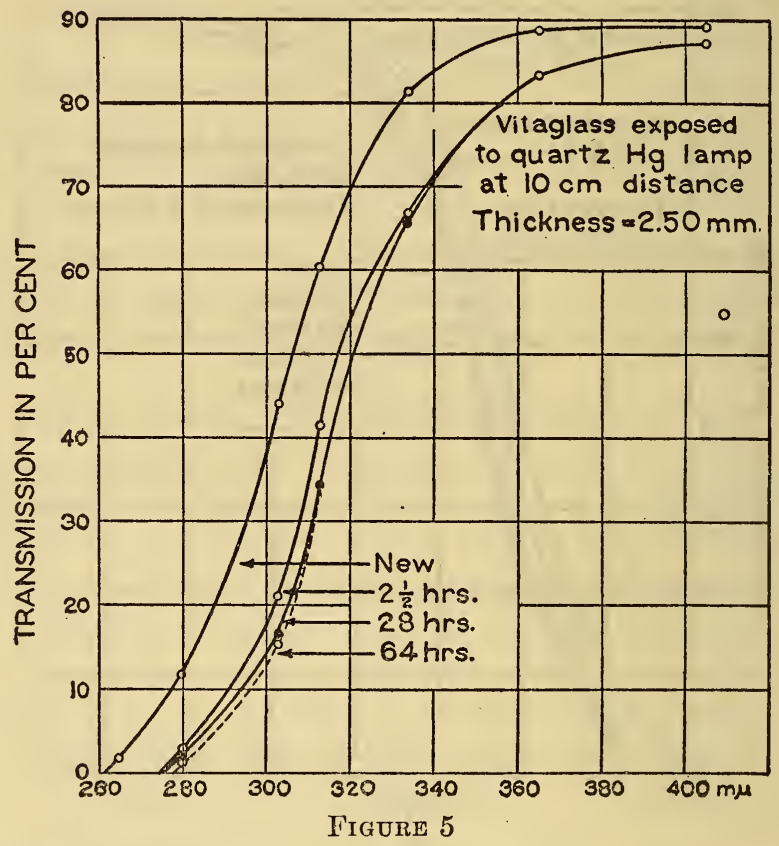

was placed about $3 \mathrm{~m}$ above the ground on the north side of a long, 4-story building, decreased in transmission from 45 to 39 per cent at $302 \mathrm{~m} \mu$ after an exposure of one month (December, 1927), and to 31 per cent by a year (December, 1928).

The solarization data obtained at the higher altitude, at Flagstaff, Ariz., are interesting in showing that after prolonged exposure the average transmission of the glasses (see Table 5) is practically the same as that obtained at Washington. A typical example of the change in transmission after an exposure to the sun for about eight weeks (March 12 to May 7, 1928) is shown in Figure 8. The average transmission of two samples for wave length $302 \mathrm{~m} \mu$ after exposure to the sun from March to May at Flagstaff, Ariz., was 21.4 per cent 
$(t=2.55 \mathrm{~mm})$ and the transmission of duplicate samples exposed at the same time in Washington was 22.2 per cent. The results as a whole show that this type of Vitaglass solarizes very quickly. This is further verified by the tests with artificial radiation.

\section{(b) EFFECT OF ARTIFICIAL LIGHT}

The effect of ultra-violet light from artificial sources of radiation is practically the same as that of sunlight upon the ultra-violet transmission of Vitaglass; the only difference being the rate of change, which is more rapid with the quartz mercury arc than with the sun.

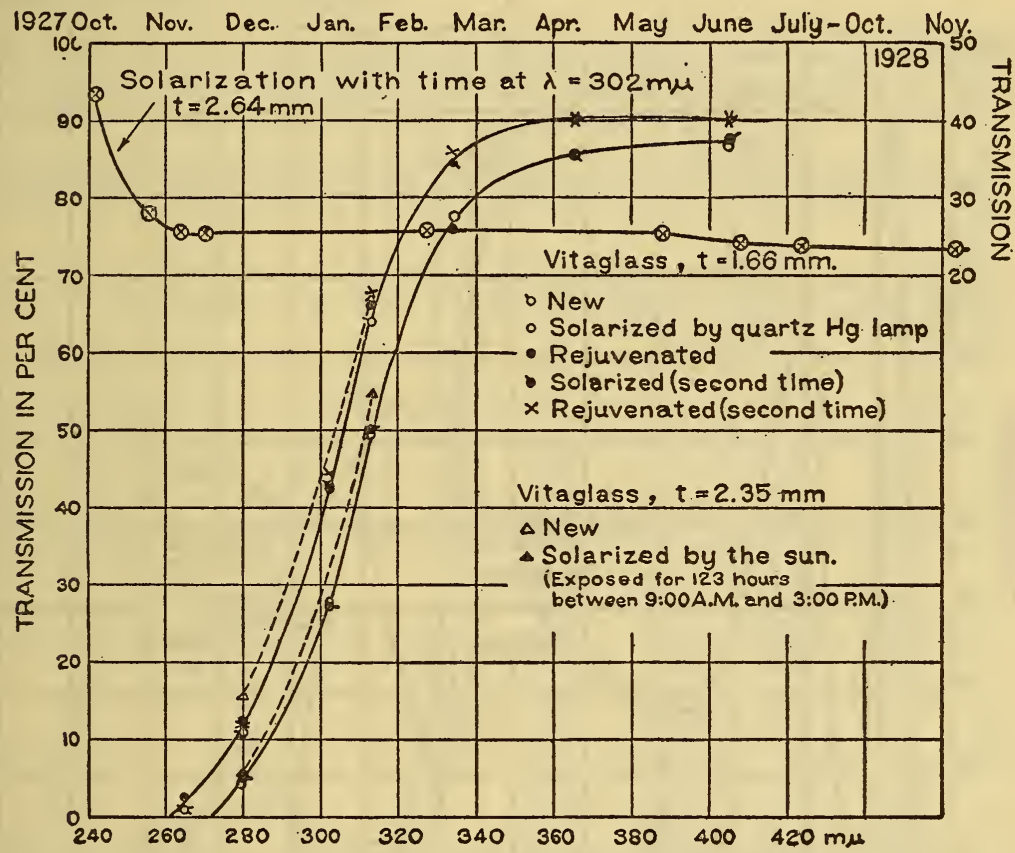

FIGURE 6.-Solarization of Vitaglass with time, upper curve

The carbon arc (including the "Fad-Ometer," dye-fading carbon arc which is surrounded with a glass chimney that is opaque to ultraviolet radiation of wave lengths less than $310 \mathrm{~m} \mu$, see fig. 12 and Table 6) also decreases the ultra-violet transmission of this glass; for example, two samples of Vitaglass (Table 7, $t=2.3 \mathrm{~mm}$ ) which transmitted 34.6 and 40.3 per cent, respectively, at $302 \mathrm{~m} \mu$ when new, decreased in transmission to 19 and 23 per cent, respectively, after an exposure of 300 hours to a white flame carbon arc, and to 18 and 20 per cent, respectively, on a further exposure of 10 hours to the mercury lamp.

As shown in Figure 5, exposure of Vitaglass to ultra-violet radiation from the quartz mercury arc produces practically the same kind of photochemical action as sunlight, the only difference being the time 
involved. In other respects these two sets of transmission curves (obtained on two samples cut from the same sheet of glass, figs. 4 and 5) are practically superposable. The average transmission of Vitaglass at $302 \mathrm{~m} \mu$ after complete photochemical stabilization by exposure to the mercury arc is about 23 per cent for a thickness of $2.3 \mathrm{~mm}$. (See Table 2.)

As is well known, different melts of glass vary in purity and, hence, in transmission of ultra-violet radiation. Samples of Vitaglass of the most recent importation (January, 1929) had a transmission of about 62 per cent (for $t=2.3 \mathrm{~mm}$, samples $1 \mathrm{j}$ to $3 \mathrm{j}$, Table 4 ) when

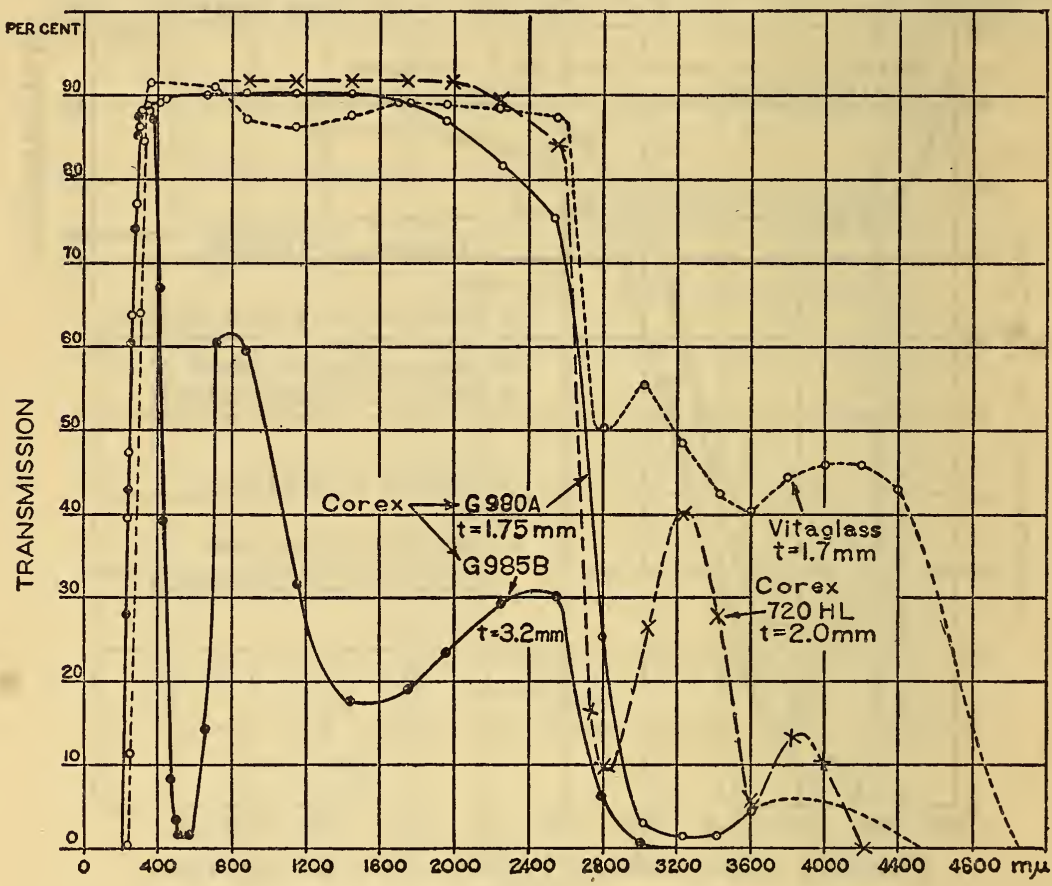

FIGURE 7.-Infra-red transmission of window glasses

new and about 30 per cent after complete stabilization under the mercury arc.

It is relevant to add that the transmission of Vitaglass appears to undergo a somewhat greater decrease in the region of 320 to $380 \mathrm{~m} \mu$ as a result of exposure to the quartz mercury arc than to the sun. However, this part of the ultra-violet spectrum is not known to have special vitalizing properties. Hence, the question of the method of solarization is relatively unimportant, especially so when it is known that glasses can be made which have a higher transmission after the most severe photochemical stabilization by the mercury arc than some of the most transparent samples now obtainable, when new. This is 
the most severe test that can be applied and manufacturers may well be proud of their ability to produce a glass that withstands this test.

\section{(c) INFRA-RED TRANSMISSION}

The complete spectral transmission curve of Vitaglass is depicted in Figure 7 from which it may be seen that its transmission in the infra-red is much the same as common window glass having the same thickness. (Fig. 14.) The relatively high transmission beyond $4,000 \mathrm{~m} \mu$ is unimportant because the infra-red solar radiation of wave lengths longer that $4,000 \mathrm{~m} \mu$ is less than 0.5 per cent of the total incident solar radiation.

TABLE 4.-Decrease in transmission of window glasses at wave length $302 \mathrm{~m} \mu$ on exposure to the Sun in Washington (except Helioglass No. 2a and Corex-A, which were at Flagstaff, Ariz., and $1 \mathrm{~m}$ which was on Long Island)

[The exposure of 258 days extended from February to November 15 . The shortest exposures (89 days) extended from August 17 to November 15, 1928. Duplicate samples were exposed to the mercury arc.]

\begin{tabular}{|c|c|c|c|c|c|}
\hline Sample & Thickness & $\begin{array}{l}\text { Trans- } \\
\text { mission } \\
\text { when } \\
\text { new }\end{array}$ & $\begin{array}{l}\text { Trans- } \\
\text { mission } \\
\text { after ex- } \\
\text { posure to } \\
\text { sun }\end{array}$ & $\begin{array}{c}\text { Time } \\
\text { exposed }\end{array}$ & $\begin{array}{l}\text { Trans- } \\
\text { mission } \\
\text { after ex- } \\
\text { posure to } \\
\text { mercury } \\
\text { lamp for } \\
10 \text { hours }\end{array}$ \\
\hline $\begin{array}{l}\text { Vitaglass: } \\
2 \mathrm{a} a \\
1 \mathrm{~b} a \\
1 \mathrm{~b}\end{array}$ & $\begin{array}{l}m m \\
2.65 \\
2.65 \\
2.43 \\
2.43 \\
2.01\end{array}$ & $\begin{array}{r}\text { Per cent } \\
44.6 \\
44.6 \\
-\end{array}$ & $\begin{array}{r}\text { Per cent } \\
24.1 \\
23.3 \\
27.5 \\
26.7 \\
26.5\end{array}$ & $\begin{array}{l}\text { Days } \\
425 \\
654 \\
395 \\
624 \\
365\end{array}$ & $\begin{array}{r}\text { Per cent } \\
16.3 \\
-18.6 \\
-12 . \overline{8}\end{array}$ \\
\hline $\begin{array}{l}1 \mathrm{r} \\
1 \mathrm{~b} \\
\mathrm{1} h \mathrm{~h}\end{array}$ & $\begin{array}{l}2.50 \\
2.50 \\
2.55 \\
2.55 \\
2.55\end{array}$ & $\begin{array}{l}51.9 \\
51.9 \\
40.5 \\
40.5 \\
39.3\end{array}$ & $\begin{array}{l}34.8 \\
32.5 \\
20.9 \\
19.6 \\
20.8\end{array}$ & $\begin{array}{l}258 \\
487 \\
258 \\
487 \\
216\end{array}$ & $18 . \overline{5}$ \\
\hline 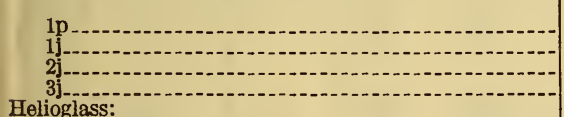 & $\begin{array}{l}3.35 \\
2.30 \\
1.98 \\
2.26\end{array}$ & $\begin{array}{l}55.5 \\
62.4 \\
65.3 \\
61.1\end{array}$ & $\begin{array}{r}35.4 \\
\\
\hdashline\end{array}$ & $\begin{array}{r}239 \\
\\
\hdashline\end{array}$ & $\begin{array}{l}20.2 \\
30.3 \\
34.3 \\
29.8\end{array}$ \\
\hline $2 \mathrm{p}$ & $\begin{array}{l}2.55 \\
2.55 \\
2.32 \\
1.75 \\
1.70 \\
2.55\end{array}$ & $\begin{array}{l}57.3 \\
57.3 \\
59.0 \\
61.3 \\
56.0 \\
51.9\end{array}$ & $\begin{array}{l}50.7 \\
48.5 \\
52.9 \\
48.9 \\
45.8 \\
42.7\end{array}$ & $\begin{array}{l}258 \\
487 \\
238 \\
445 \\
231 \\
258\end{array}$ & 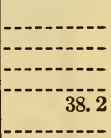 \\
\hline $\begin{array}{l}4 \mathrm{a} \\
5 \mathrm{~h} \\
6 \mathrm{~h} \\
6 \mathrm{~h}\end{array}$ & $\begin{array}{l}1.99 \\
2.20 \\
2.60 \\
2.60 \\
2.20 \\
2.20\end{array}$ & $\begin{array}{l}61.7 \\
56.3 \\
50.6 \\
50.6 \\
58.2 \\
58.2\end{array}$ & $\begin{array}{l}52.7 \\
45.1 \\
37.2 \\
35.0 \\
46.4 \\
45.8\end{array}$ & $\begin{array}{l}251 \\
261 \\
231 \\
460 \\
231 \\
460\end{array}$ & $\begin{array}{r}35.2 \\
27.9 \\
42.4 \\
-7-.-\end{array}$ \\
\hline 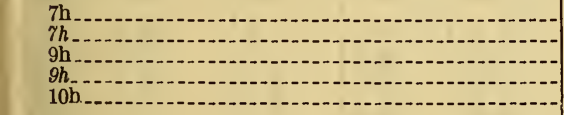 & $\begin{array}{l}2.00 \\
2.00 \\
1.90 \\
1.90 \\
1.88\end{array}$ & $\begin{array}{l}58.0 \\
58.0 \\
58.6 \\
58.6 \\
58.5\end{array}$ & $\begin{array}{l}46.2 \\
43.7 \\
47.1 \\
45.8 \\
47.8\end{array}$ & $\begin{array}{l}231 \\
460 \\
107 \\
336 \\
107\end{array}$ & $\begin{array}{r}36.7 \\
-34.2 \\
-37 . \overline{1}\end{array}$ \\
\hline ( & $\begin{array}{l}1.77 \\
1.95 \\
1.81 \\
1.93 \\
2.60\end{array}$ & $\begin{array}{l}45.0 \\
42.5 \\
43.4 \\
43.4 \\
69.1\end{array}$ & $\begin{array}{r}36.4 \\
33.7 \\
35.1 \\
33.8\end{array}$ & $\begin{array}{l}89 \\
89 \\
89 \\
89\end{array}$ & $\begin{array}{l}28.0 \\
25.5 \\
26.6 \\
27.2 \\
48.0\end{array}$ \\
\hline $\begin{array}{l}18 \mathrm{~h} \\
1 \mathrm{k} \\
\mathrm{k} \mathrm{k} \\
4 \mathrm{k}\end{array}$ & $\begin{array}{l}2.60 \\
2.25 \\
2.27 \\
2.25 \\
2.25\end{array}$ & $\begin{array}{l}67.4 \\
66.9 \\
65.9 \\
62.9 \\
67.0\end{array}$ & 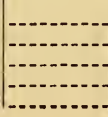 & - & $\begin{array}{l}45.7 \\
48.1 \\
48.8 \\
49.3 \\
50.0\end{array}$ \\
\hline
\end{tabular}


TABLE 4.-Decrease in transmission of window glasses at wave length 302 $m \mu$ on exposure to the sun in Washington (except Helioglass No. $2 a$ and Corex- $A$, which were at Flagstaff, Ariz., and $1 \mathrm{~m}$ which was on Long Island)-Continued

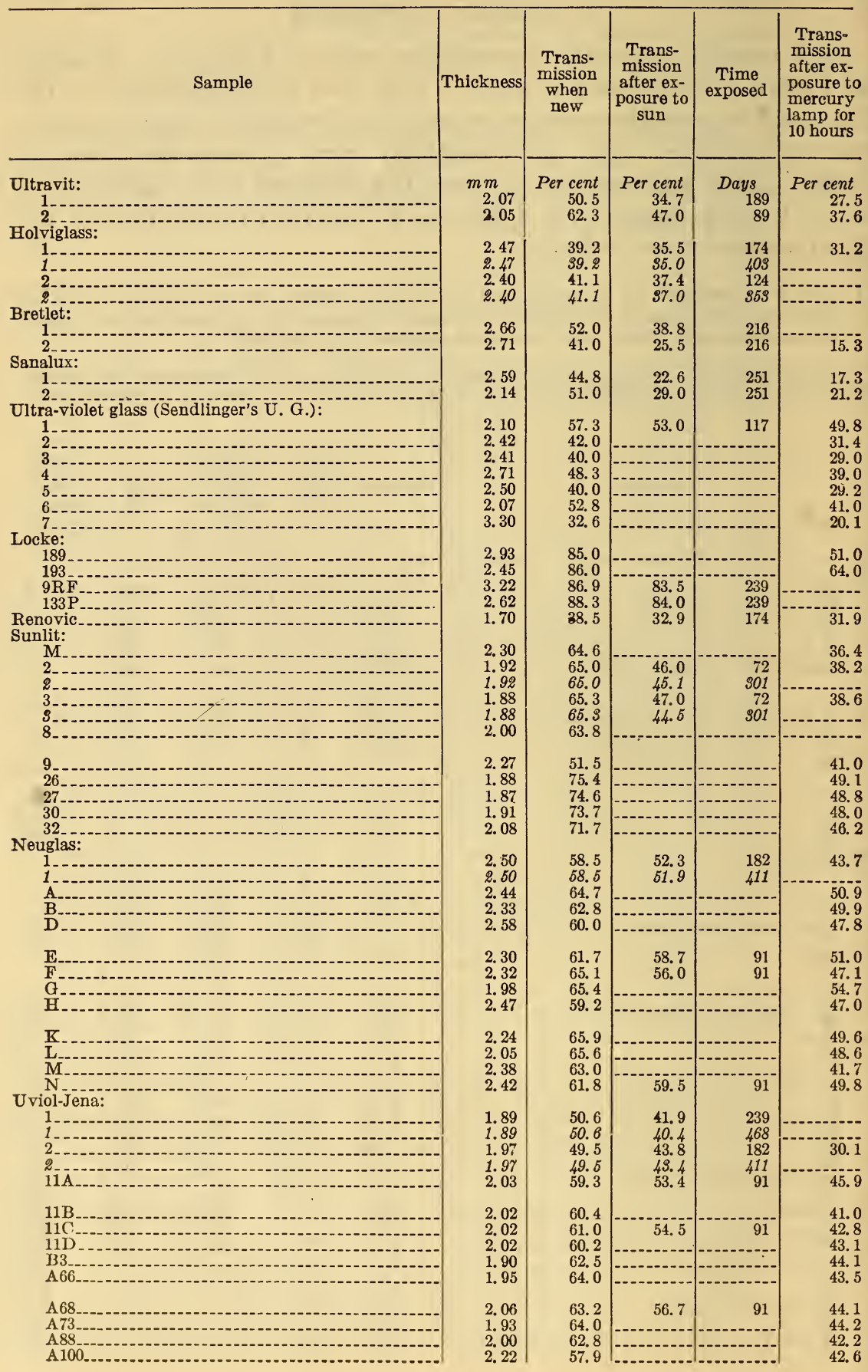


TABLE 4.-Decrease in transmission of window glasses at wave length $302 \mathrm{~m} \mu$ on exposure to the sun in Washington (except Helioglass No. 2a and Corex-A, which were at Flagstaff, Ariz., and $1 \mathrm{~m}$ which was on Long Island)-Continued

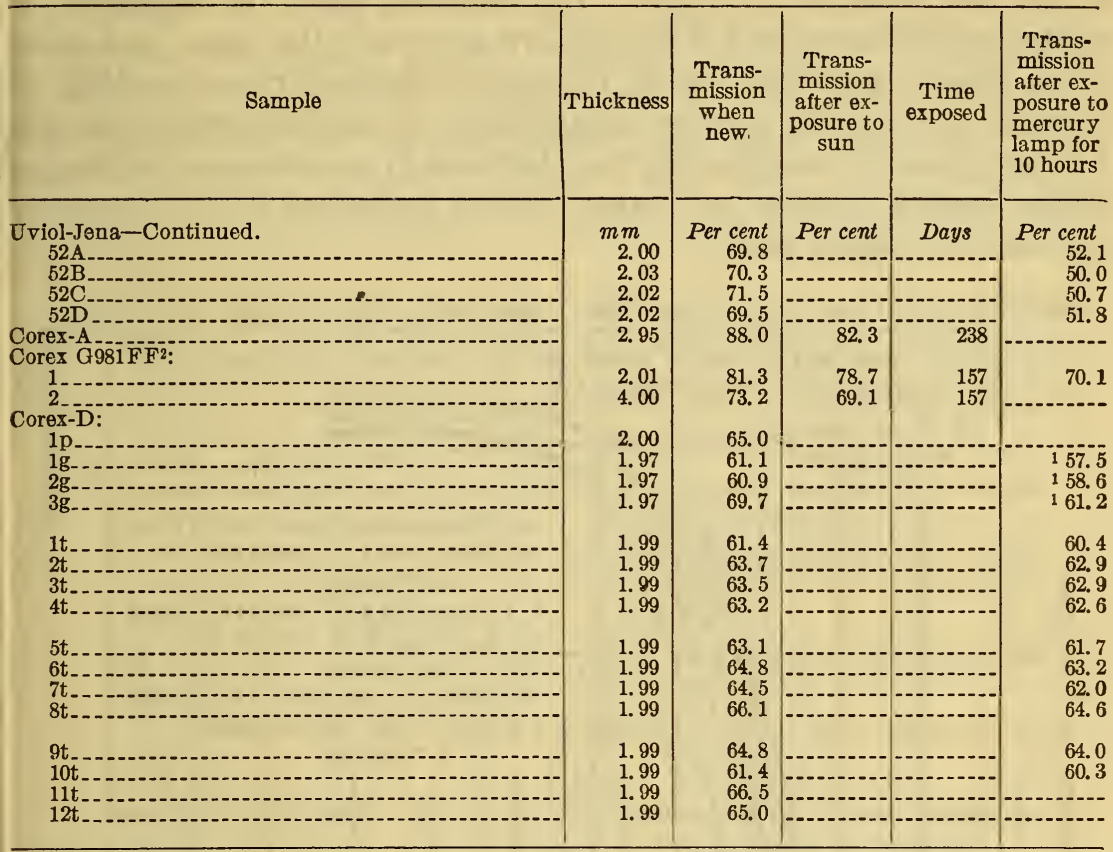

1 These 3 samples were exposed for 30 hours at a distance of $15 \mathrm{~cm}$ from a quartz mercury arc lamp.

TABLE 5.-Transmission of duplicate samples of window glasses at wave length 302 $m \mu$ before and after exposure to the sun at Flagstaff, Ariz., and in Washington, $D$. C., and after exposure to the mercury lamp at a distance of $10 \mathrm{~cm}$

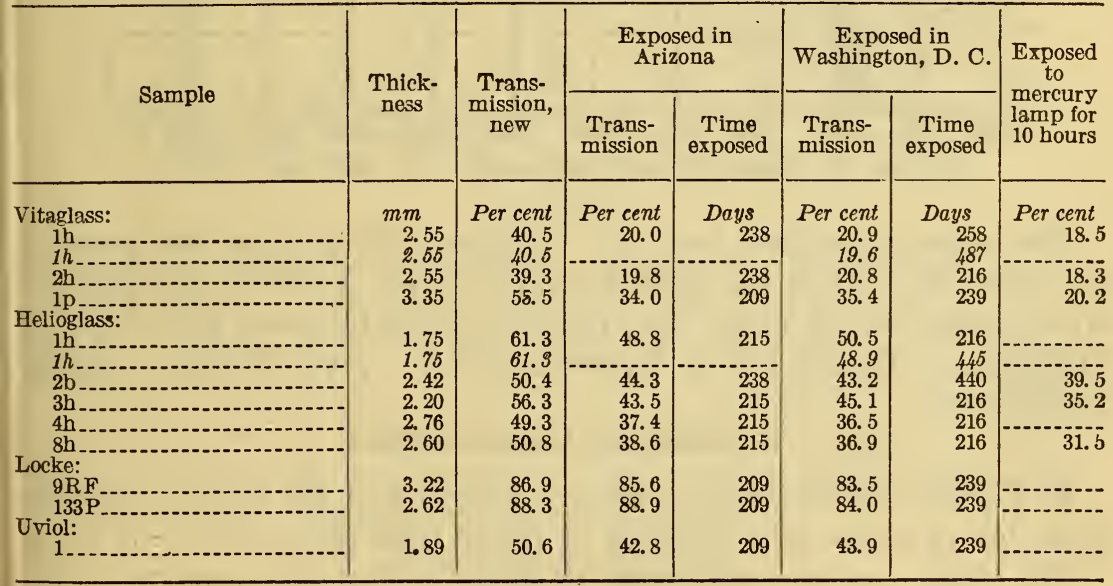




\section{HELIOGLASS}

This glass appeared on the market late in 1927 when intense sunshine was no longer available. Furthermore, since the transmission curves of Helioglass and Vitaglass are so closely the same, and since these glasses appeared to be of somewhat similar composition, it seemed fair to make the first comparisons of solarization of these two kinds of glass by accelerating the decrease in transmission by means of the quartz mercury arc lamp, which procedure is vindicated by our recent sunlight tests.

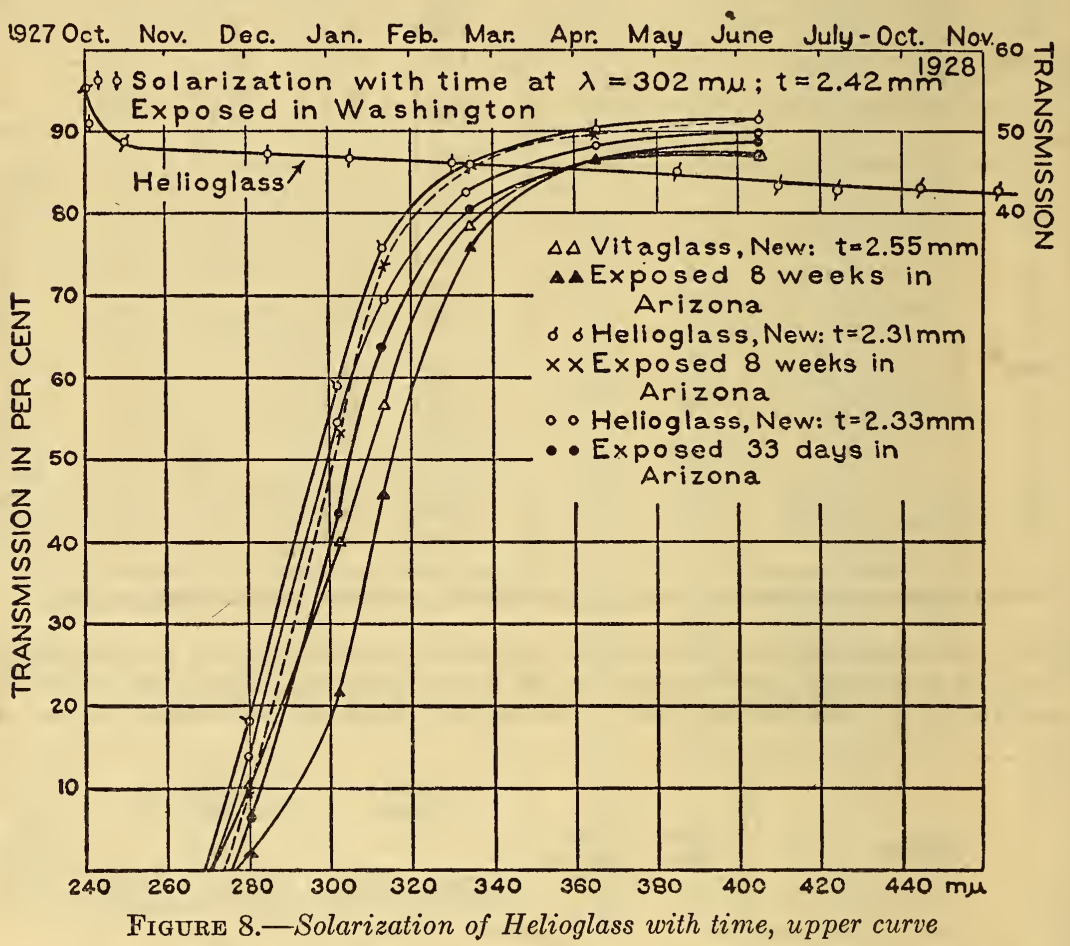

The above-described tests on Vitaglass, when using the mercury arc, also the carbon arc with a chimney (see Table 6), solarization by exposure to the north sky, rejuvenation, etc., were made also on Helioglass. Hence, it is unnecessary to give further detailed descriptions.

\section{(a) EFFECT OF ARTIFICAL LIGHT}

In Figure 9, is shown the effect of exposure of the sample of Helioglass for 72 hours at a distance of $10 \mathrm{~cm}$ from the mercury arc lamp.

The data now on hand seem to indicate that on exposure to the quartz mercury arc, Helioglass does not decrease in transmission quite so rapidly as Vitaglass; also, that after complete photochemical 
stabilization the transmission in the region of 320 to $380 \mathrm{~m} \mu$ is not as low as observed in Vitaglass.

As might be expected the various shipments of Vitaglass and Helioglass, representing melts of different batches of the same kind of material, differ greatly in transmission. (See Tables 4 and 5.) For example, several samples marked Helioglass (Table 4, $11 \mathrm{~h}$ to $16 \mathrm{~h}$ ), which had a slightly yellowish tint when viewed edgewise, transmitted less than 30 per cent at $302 \mathrm{~m} \mu$ after stabilization under the mercury lamp.

However, as viewed edgewise, Helioglass is usually colorless, "water white," and the transmission of such samples, after degeneration under the mercury lamp, ranges from 38 to 42 per cent (Table 4 ,

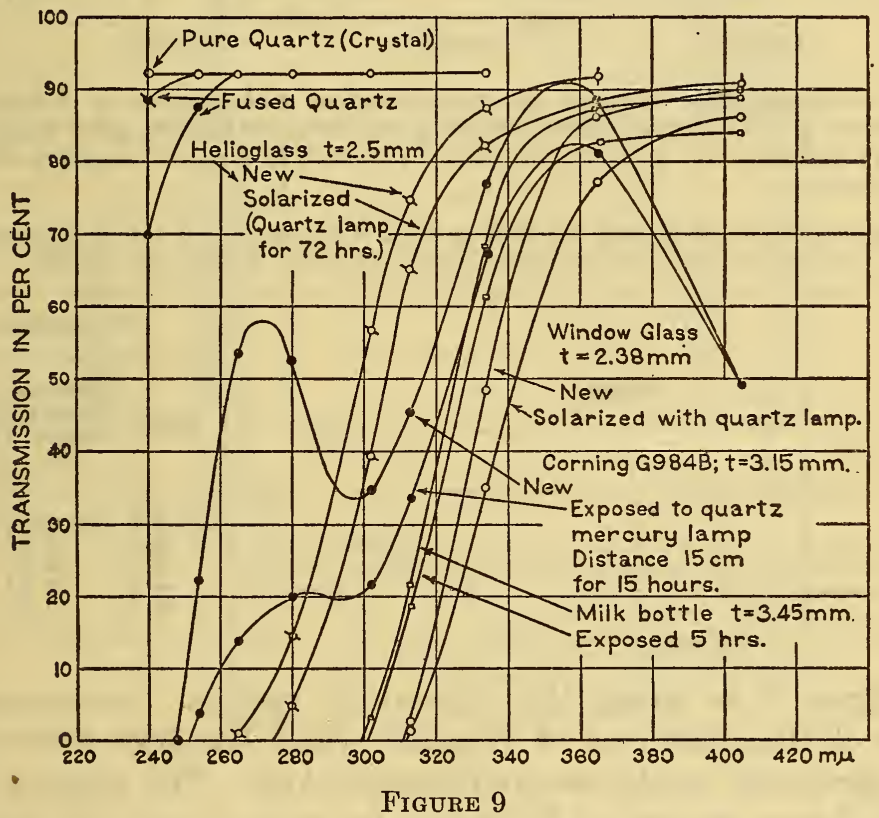

$6 \mathrm{~h}$, and $7 \mathrm{~h}$ ), while the most recent shipment tested (Table 4, 17h, and 18h, January, 1929) had a transmission of 48 per cent, or 51 per cent for a thickness of $2.3 \mathrm{~mm}$. This is a decided improvement in the quality of this glass. However, the transmission of the general run of Helioglass, at $302 \mathrm{~m} \mu$, after complete photochemical stabilization by the mercury arc appears to be between 35 and 40 per cent for a thickness of $2.3 \mathrm{~mm}$. (Tables 2,4 , and 7.)

(b) EFFECT OF SUNLIGHT

Our investigations show that, on exposure to the sun, Helioglass does not solarize and decrease so low in transmission as Vitaglass (41). This is in agreement with the observations on the accelerated stabilization under the mercury arc. 
TABLE 6.-Comparative data on the transmission (at $302 \mathrm{~m} \mu$ ) of duplicate samples of Vitaglass and Helioglass after exposure to the Fad-Ometer, to the mercury arc (distance $10 \mathrm{~cm})$, and to the sun.

\begin{tabular}{|c|c|c|c|c|c|c|c|}
\hline V & \multirow[t]{2}{*}{ Sample } & \multirow[t]{2}{*}{$\begin{array}{l}\text { Thick- } \\
\text { ness }\end{array}$} & \multirow{2}{*}{$\begin{array}{c}\text { Trans- } \\
\text { mission } \\
\text { when } \\
\text { new }\end{array}$} & \multicolumn{2}{|c|}{$\begin{array}{l}\text { Transmission aft- } \\
\text { er exposure to } \\
\text { F a d - O meter } \\
\text { carbon arc (glass } \\
\text { chimney) }\end{array}$} & \multirow{2}{*}{$\begin{array}{l}\text { Trans- } \\
\text { mission } \\
\text { after ex- } \\
\text { posure to } \\
\text { sun }\end{array}$} & \multirow{2}{*}{$\begin{array}{l}\text { Trans- } \\
\text { mission } \\
\text { after ex- } \\
\text { posure of } \\
10 \text { hours } \\
\text { to mer- } \\
\text { cury } \\
\text { lamp }\end{array}$} \\
\hline & & & & $\begin{array}{c}1,500 \\
\text { hours at } \\
15 \text { inches }\end{array}$ & $\begin{array}{c}3,000 \\
\text { hours at } \\
15 \text { inches }\end{array}$ & & \\
\hline $\begin{array}{r}\text { Vitaglass: } \\
\text { 1d } \\
\text { 2h }\end{array}$ & - & $\begin{array}{l}m m \\
2.23 \\
2.55\end{array}$ & $\begin{array}{r}\text { Per cent } \\
47.4 \\
39.3\end{array}$ & $\begin{array}{r}\text { Per cent } \\
37.9 \\
30.4\end{array}$ & $\begin{array}{r}\text { Per cent } \\
37.7\end{array}$ & $\begin{array}{r}P e r \text { cent } \\
130.3 \\
220.8\end{array}$ & $\begin{array}{r}\text { Per cent } \\
21.1 \\
18.3\end{array}$ \\
\hline $\begin{array}{r}\text { Helioglass: } \\
3 \mathrm{a} \text { :--- } \\
5 \mathrm{~h}\end{array}$ & & $\begin{array}{l}2.02 \\
2.60\end{array}$ & $\begin{array}{l}57.7 \\
50.6\end{array}$ & $\begin{array}{l}52.5 \\
41.6\end{array}$ & 51.4 & 337.2 & 27.9 \\
\hline
\end{tabular}

TABLE 7.-Comparative data on the photochemical stabilization of Vitaglass by exposure to a white flame carbon arc lamp for about 300 hours, after which treatment the samples were given an additional exposure to a quartz mercury arc lamp for 10 hours

[The distance from the carbon are lamp was $20 \mathrm{~cm}$ for $1 \mathrm{t}$ and $2 \mathrm{t}$, and $30 \mathrm{~cm}$ for $1 \mathrm{~b}$ and $2 \mathrm{~b}$; distance from the mercury arc lamp $15 \mathrm{~cm}$; thickness $2.3 \mathrm{~mm}$; transmission in per cent at $302 \mathrm{~m} \mu$ ]

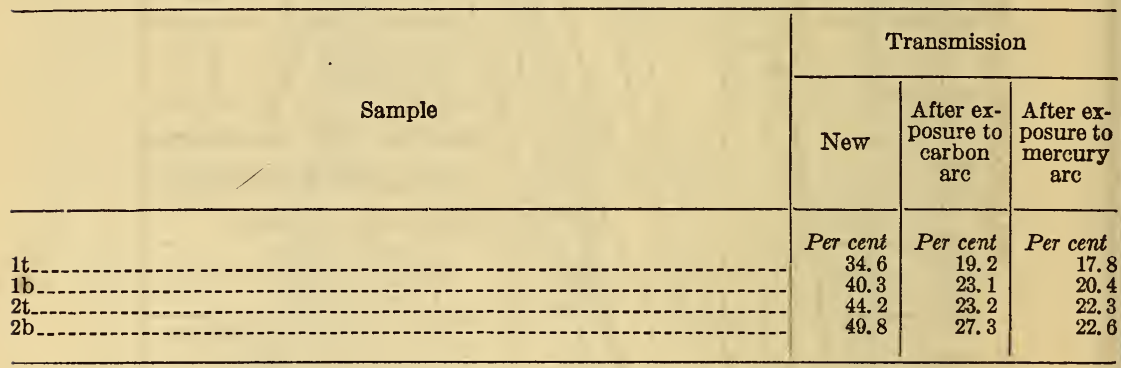

In Figure 8 is shown the ultra-violet spectral transmission of samples of Helioglass and of Vitaglass which had been exposed (at $45^{\circ}$ facing south) to the sun at Flagstaff, Ariz. The average transmission of two samples of Helioglass for wave length $302 \mathrm{~m} \mu$ after exposure at Flagstaff for about eight weeks (March 12 to May 7, 1928, see fig. 8) is 49.4 per cent $(t=2.35 \mathrm{~mm}$ ) as compared with 23.8 per cent (21.4 per cent for $t=2.55 \mathrm{~mm}$ ) for two samples of Vitaglass similarly exposed to the sun.

In Figure 8 the circles and dots $(0$ o $o, \ldots$ ) show the average transmission of four samples of Helioglass that were exposed to the sun for 33 days (April 4 to May 7, 1928) at Flagstaff, Ariz. These four samples seemed to decrease more in transmission than the preceding two samples which were exposed for eight weeks, the average transmission of the four samples at $302 \mathrm{~m} \mu$ being 43.7 per cent ( $t=$ $2.33 \mathrm{~mm}$ ) while duplicates of these four samples, after being exposed in Washington for 25 days (April 12 to May 7, 1928), transmitted 
44.5 per cent. The difference in the amount of solarization at Flagstaff and at Washington is no doubt to be ascribed to the greater amount of ultra-violet radiation at the higher altitude. However, as already noted, after prolonged exposure there is practically no difference in the solarization at the two stations.

From the slope of the curve in the upper part of Figure 8 which shows the decrease in transmission at $302 \mathrm{~m} \mu$ with time, it appears that the solarizarion of Helioglass after 13 months' exposure is still incomplete. Hence, it can not be stated definitely what the average

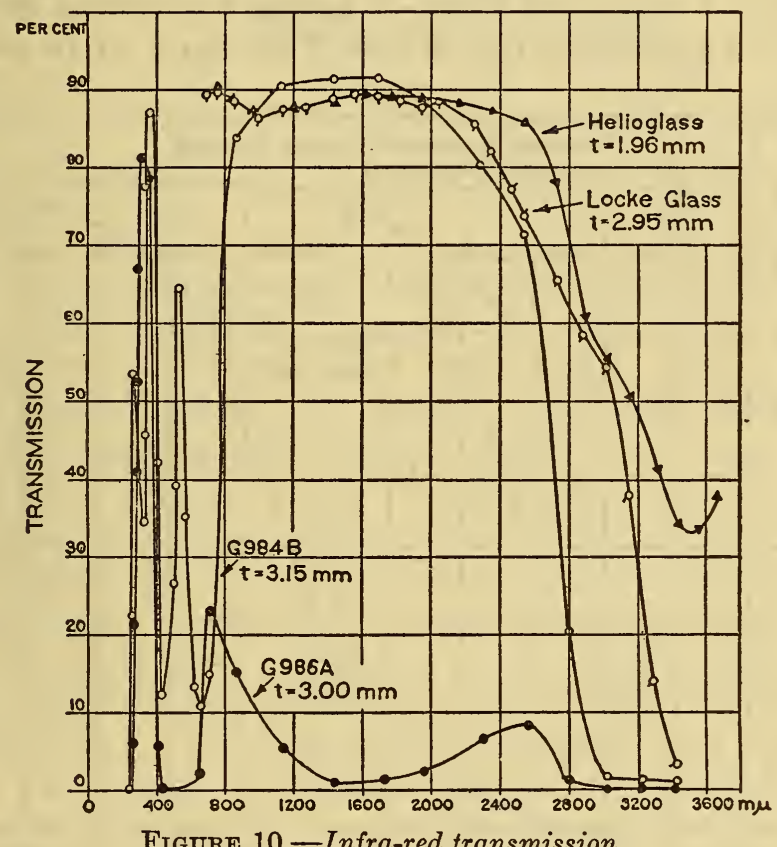

Figure 10.-Infra-red transmission

transmission will be after complete solarization. However, extrapolation of the exposure time curve in the upper part of Figure 8 indicates a transmission of about 40 per cent after complete solarization of this sample. Further exposure of this sample to the mercury arc reduced the transmission from 43 to 39.5 per cent, which is in agreement with the extrapolated value. (See also Table 4.)

The infra-red transmission of Helioglass (extending to $3,600 \mathrm{~m} \mu$ ) is illustrated in Figure 10, which shows that, for the same thickness, it is similar to that of common window glass. The ultra-violet transmission of the solarized material is depicted in Figure 15. 


\section{COREX-A GLASS}

The trade name of the glasses for transmitting ultra-violet radiation, made by the Corning Glass Works, is Corex. There are several distinct types of this glass, Corex-A, Corex-B, etc., depending upon the chemical composition and its intended use.

(a) EFFECT OF SUNLIGHT

The glass called Corex-A (Corning G980A) appears to undergo no appreciable change in transmission when exposed to solar radiation. For example, a sample of Corex-A having a cathedral finish which had been in a greenhouse roof in New York State for 14 months was

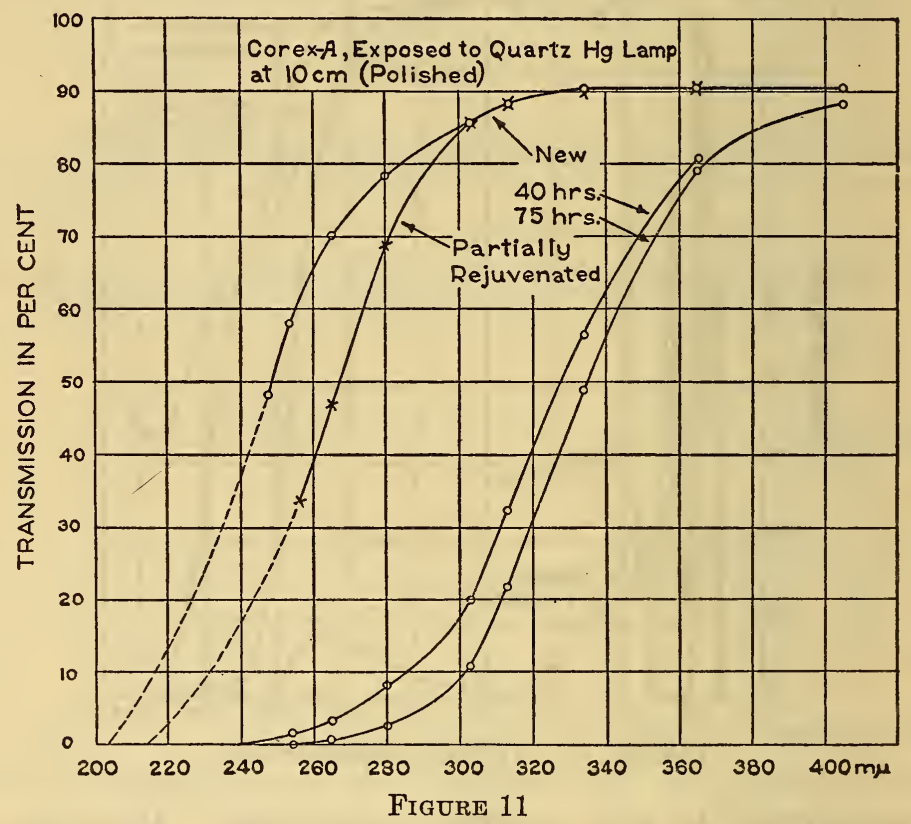

found to have, as nearly as could be measured on that kind of surface (which had been roughened by moisture), the same transmission as a new sample. It was then polished plane and found to have a transmission of 89.5 per cent at $302 \mathrm{~m} \mu$, while the average transmission of several new samples, as given in Table 1 , is 89 per cent.

As already mentioned, the constancy in the transmission is probably owing to the fact that this glass absorbs but little (transmission $=91$ per cent for the most homogeneous samples) in the spectral range of solar radiation. Similar results were obtained at higher altitudes, hence, included shorter wave lengths of ultra-violet solar rays. For example, a sample of Corex-A $(t=4.5 \mathrm{~mm})$ after an exposure of about six weeks (February 28 to April 10, 1928) at the Desert Lab- 
oratory, Tucson, Ariz. (elevation 2,360 feet), had a transmission of 87 per cent at $302 \mathrm{~m} \mu$, which value would have been still higher if allowance had been made for scattering of the rays by the very noticeable inhomogeneity of the glass. Another sample exposed at Flagstaff, Ariz. (elevation 7,250), from March to November, 1928, (238 days) transmitted 83 per cent at $302 \mathrm{~m} \mu$, as compared with 88 per cent when new, the lower value being due mainly to the diffusing effect of the roughened surface of the glass. From the results at hand it is evident that it will require a very prolonged exposure to the sun in order to affect the transmission.

\section{(b) EFFECT OF ARTIFICIAL LIGHT}

In contrast with the constancy of the transmission under exposure to sunlight, exposure to the short wave-length radiation from the quartz mercury are (at $250 \mathrm{~m} \mu$ where the absorption begins to be appreciable) causes a very marked decrease in the transmission of ultra-violet radiation through Corex-A glass. As a result of exposure to the mercury arc lamp, this glass takes on a reddish color and greatly decreases in transmission throughout the ultra-violet of wave lengths less than $360 \mathrm{~m} \mu$. (Fig. 11.) This reddish color is most intense at the exposed surface, and decreases in intensity with the distance from the exposed surface into the interior of the glass.

Prolonged exposure to the "Fad-Ometer" carbon arc which was surrounded with a glass chimney (Fig. 12) that absorbed all the rays of wave lengths less than $310 \mathrm{~m} \mu$, had no effect upon the ultra-violet transmission of Corex-A glass, as is to be expected since this material seems to be perfectly transparent in this spectral region.

The infra-red transmission of Corex-A (G980A, $t=1.75 \mathrm{~mm}$ ) is given in Figure 7 , which shows that this glass is very opaque to radiation of wave lengths longer than $3,200 \mathrm{~m} \mu$. A homogeneous sample 2 $\mathrm{mm}$ in thickness should, therefore, prove useful as a screen in astronomical radiometry (42) in addition to the quartz which is opaque to wave lengths greater than about $4,100 \mathrm{~m} \mu$, and the screen of Pollopas, (43) which in thicknesses of $10 \mathrm{~mm}$ is opaque to radiation of wave lengths greater than $1,600 \mathrm{~m} \mu$.

\section{COREX GLASS, G981FF²}

Through the courtesy of the Corning Glass Works, we have been able to test an experimental sample of window glass which has a high transmission at $302 \mathrm{~m} \mu$ and is resistant to weathering and to solarization. The sample examined had a transmission of 78.7 per cent $(t=2.01 \mathrm{~mm})$ after an exposure of five months (June to November, 1928) as compared with 81.3 per cent when new. The stability in transmission under the mercury are is equally favorable.

A comparison of the ultra-violet transmission of this solarized sample Corex G981FF with other glasses is illustrated in Figure 15 . 


\section{COREX-D GLASS}

The Corning glasses which are designed to have a sharp cut-off at about $290 \mathrm{~m} \mu$ are designated Corex-D. One of these new heat resisting, ultra-violet transmitting glasses, G720HL (fig. 2, HL) was found to change but little in transmission on exposure to the quartz mercury arc. Hence, this promises to be a useful filter, to be placed over lamps emitting excessive amounts of ultra-violet of wave lengths less than about $290 \mathrm{~m} \mu$. The infra-red transmission of this glass is given in Figure 7.

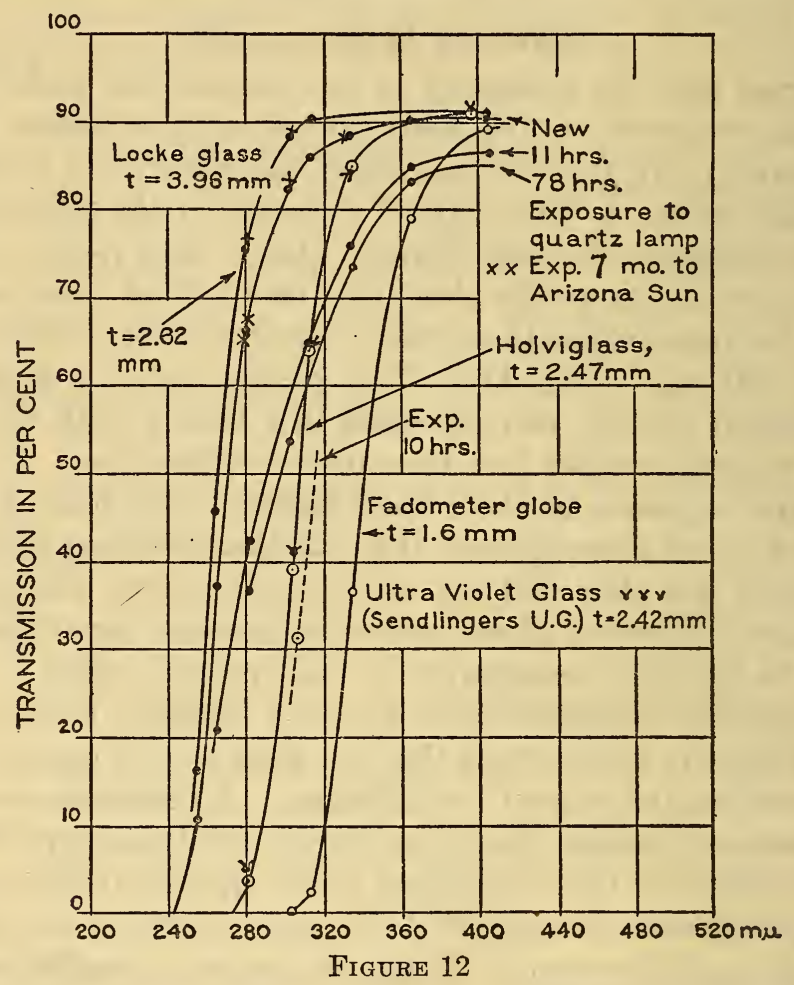

In Figure 2 is shown the average transmission curve of three samples of Corex-D glass. These samples represent three melts, on a commercial basis, extending over a period of about two months and appear to be representative of what may be expected of this type of glass produced on a commercial scale. Further data on a dozen samples of different melts, observed at $302 \mathrm{~m} \mu$, are given in Table 4.

In Figure 15 is shown the spectral transmission of the average of these three samples of Corex-D after exposure to the radiation from a quartz mercury arc lamp, at a distance of about $15 \mathrm{~cm}$ for about 30 hours. From this curve and Tables 2 and 4 it may be noticed 
that this glass decreases but little in transmission on exposure to the ultra-violet rays, the transmission after prolonged exposure being 60 per cent at $302 \mathrm{~m} \mu$ as compared with 61 per cent $(t=2.3 \mathrm{~mm})$ when new. It may be noted also that while this glass is intended primarily for windows of carbon arc lamps, its transmission at 302 $\mathrm{m} \mu$ (fig. 15) exceeds that of solarized Vitaglass and Helioglass, and is useful also for windows in solariums.

\section{ULTRA-VIOLET FILTERS}

In addition to the colorless screens, it is of interest to record some observations of the variation in transmission of a dark purple-colored glass filter, Corning G986A, illustrated in Figure 3 (see also a light purple-colored screen, G985B, in fig. 7) and a greenish-colored glass G984B, depicted in Figure 9. The infra-red transmissions of these two glasses are given in Figure 10.

No doubt the time will come when new glasses will be on the market which will not change in transmission. In the meantime it will be necessary to take into consideration possible changes in the short wave length ultra-violet transmission of the foregoing screens when used for isolating radiation stimuli in biological and photochemical and allied investigations.

\section{QUARTZ GLASS}

We have tested several transparent homogeneous samples of fused quartz for solarization and have found that even samples which show strong absorption (fig. 9) and fluorescence, did not decrease more than 2 per cent in transmission, at 240 and $254 \mathrm{~m} \mu$ on exposure to the quartz mercury are for 110 hours (44).

\section{LOCKE GLASS}

This is an experimental glass of interest because of its high transmission throughout the ultra-violet. (Fig. 12, $t=2.62$ and $3.96 \mathrm{~mm}$.) Even after prolonged exposure to the quartz mercury arc, the transmission remains higher than that of some of the unsolarized glasses now obtainable. Whether this same condition would obtain when the glass is made on a commercial scale, remains to be determined. As shown by the crosses (xxx) in Figure 12, this glass did not solarize on exposure to the sun for seven and one-half months (March 24 to November 5, 1928) at Flagstaff, Ariz. The sample exposed in Washington during this same period showed a small decrease (4 per cent) in transmission; but this was owing to a deterioration of this surface by moisture. The infra-red transmission of this glass, to 3,600 $\mathrm{m} \mu$, is given in Figure 10 . 


\section{QUARTZLITE GLASS}

In view of the increase in transmission which was supposed to occur on exposure of Quartzlite glass to ultra-violet radiation, tests were made to determine the effect of irradiation. In Figure 13, curve $A$ gives the results of an exposure of 10 hours to an iron arc; curve $B, 5 \frac{1}{2}$ hours to a quartz mercury arc; and curve $C, 20$ days to a "Fad-Ometer" carbon arc, which was covered with a glass chimney that absorbed all the ultra-violet of wave lengths less than 310 $\mathrm{m} \mu$. (See transmission curve in fig. 12.)

As shown in this illustration (curves $A$ and $B$ ) the ultra-violet rays of wave lengths less than $310 \mathrm{~m} \mu$ produce a small decrease in trans-

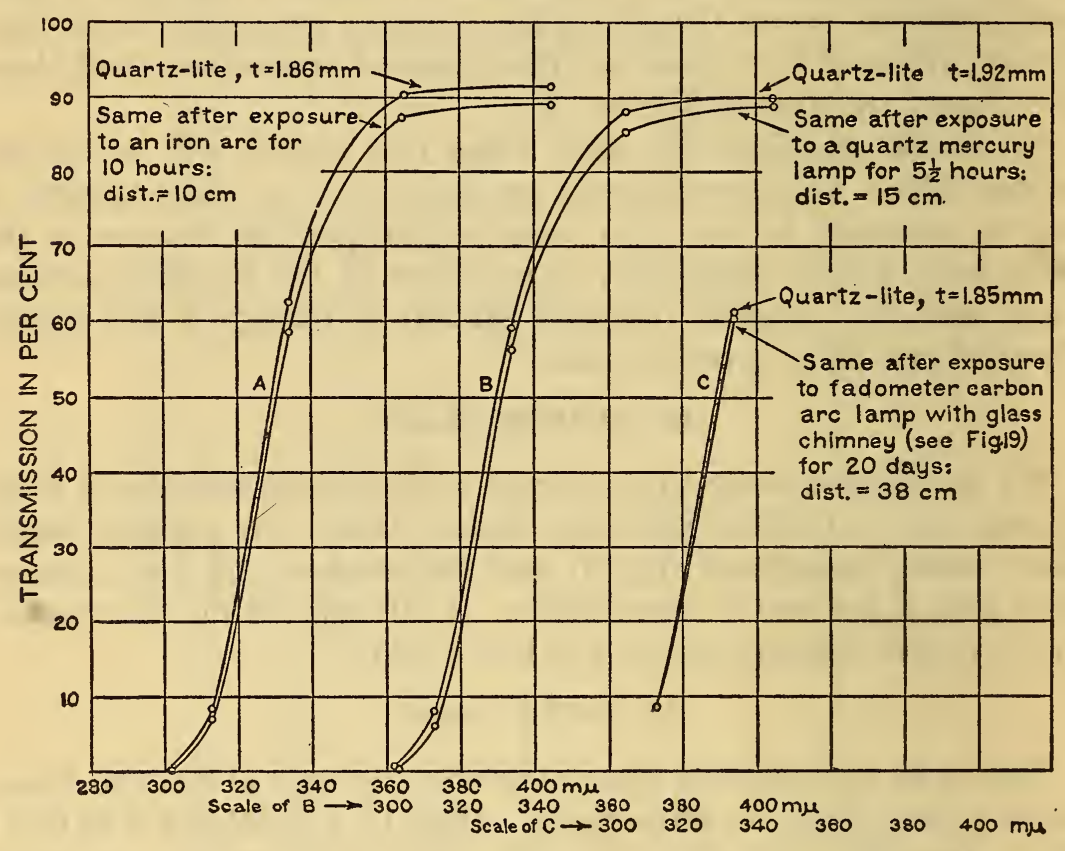

Figure 13

mission through this glass. The ultra-violet rays of wave lengths less than $302 \mathrm{~m} \mu$ do not penetrate deeply into it and the photochemical action is mainly in the production of a greenish-brown color at the surface of the glass. The color is best observed by viewing the interior of the glass by looking at it edgewise, at a grazing angle of emergence of the rays.

The results of these tests show that exposure of this glass to ultraviolet rays from artificial sources does not increase its transmission, but, under certain conditions the transmission is appreciably decreased. Exposure to the sun does not appear to change the transmission appreciably. 
The infra-red transmission of Quartzlite is illustrated in Figure 14 from which it may be seen that, for the same thickness, its transparency does not differ appreciably from that of common window glass.

\section{WINDOW GLASS AND BOTTLE GLASS}

Common window glass which is not decolorized decreases a little in transmission in the ultra-violet on exposure to the quartz mercury arc lamp. (Fig. 9.)

Common window glass and bottle glass differ only in composition to the extent that in the latter the greenish color, which is caused by the presence of iron as an impurity, is removed by some decolorizer;

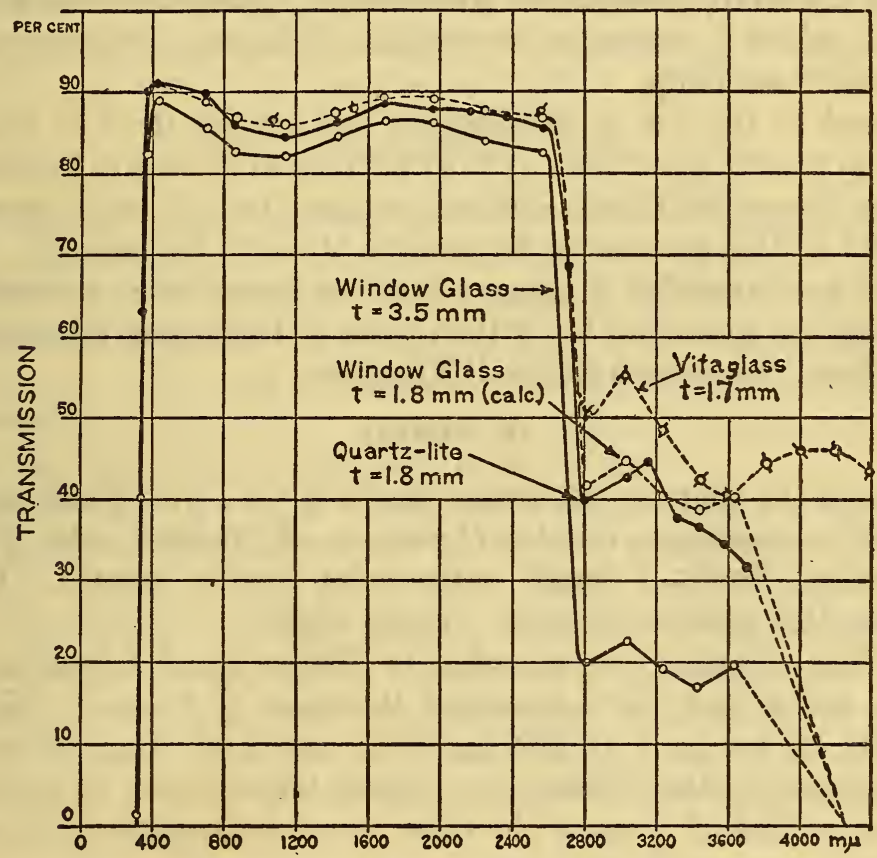

FIgURe 14.-Infra-red transmission of window glasses

for example, manganese or selenium. The effect of ultra-violet solar radiation in producing an amethyst color in a bottle glass, which presumably was decolorized with manganese, is shown in Figure 3 which gives the transmission curves of two fragments (ground and polished to a thickness of 2.22 and $2.60 \mathrm{~mm}$, respectively) of a flatwalled glass bottle, picked up some years ago on the mesa at Flagstaff, Ariz. The material had a deep amethyst color, and as shown in the dotted curve (ooo) in Figure 3, the amethyst color of the thicker sample was still further increased by exposure to the quartz mercury arc lamp.

In Figure 9 is shown the spectral transmission of a polished piece of glass from a milk bottle which was probably decolorized with $73113^{\circ}-29-4$ 
selenium. Exposure to the mercury arc seemed to affect only the surface which became yellowish-brown as viewed edgewise. This lowers the transmission throughout the visible and the ultra-violet spectrum.

\section{HOLVIGLASS}

This glass is a recent production, made by the Holophane Co. (Ltd.), London. The sample examined ( $t=2.47 \mathrm{~mm}$, fig. 12) had a transmission almost identical with that of the sample of cathedral Vitaglass $(t=2.3 \mathrm{~mm})$ illustrated in Figure 2 .

An exposure of 10 hours, at a distance of $15 \mathrm{~cm}$ from a quartz mercury arc lamp, reduced the transmission at $302 \mathrm{~m} \mu$ from 39 to 31 per cent, which is somewhat lower than Helioglass after exposure to the mercury arc lamp.

Exposed to the sun in Washington one sample $(t=2.41 \mathrm{~mm})$ decreased in transmission from 41 to 37 per cent at $302 \mathrm{~m} \mu$ in four months (July to November) and another sample $(t=2.47 \mathrm{~mm})$ decreased from 39.2 to 35.5 per cent in six months (June to November). From the data now available it appears that the transmissive properties of Holviglass are somewhat lower than those of Helioglass, but decidedly higher than (the smooth finished) Vitaglass.

\section{SUNLIT}

Through the courtesy of Semon, Bache \& Co., New York, we have been able to examine a number of samples of different melts of a new glass, called Sunlit ("Sunlit ultra-violet health glass"). Viewed edgewise, this glass is colorless, "water white."

The data obtained are recorded in Tables 2 and 4 from which it may be noted that, for a standard thickness of $2.3 \mathrm{~mm}$, this glass transmits 65 per cent at $302 \mathrm{~m} \mu$ when new and about 39 per cent after exposure to the mercury arc, which transmission is practically the same as that of some of the most recent shipments of Helioglass.

\section{NEUGLAS}

Through the courtesy of the Vitrea Co. (Inc.), New York, we have been able to examine a number of samples of different melts of a newly developed glass called Neuglas (from the Neue Glasindustr. Gesellsch.Weisswasser, O. L.).

The ultra-violet spectral transmission curve of this (unsolarized) material coincides almost exactly with that of the sample of Corex-D, depicted in Figure 2, the transmission being a trifle lower in the region of 313 to $334 \mathrm{~m} \mu$.

The transmission of Neuglas at $302 \mathrm{~m} \mu$ decreases considerably more than that of Corex-D on exposure to the ultra-violet radiation from the quartz mercury arc. As shown in Table 2, the average transmission of the samples of Neuglas examined by us (thickness $=2.3 \mathrm{~mm}$ ) 
is about 63 per cent when new, and decreases to about 49 per cent after exposure of 10 hours to the quartz mercury arc lamp.

\section{UVIOL-JENA}

Through the courtesy of the Fish-Schurman Corporation, New York, we have obtained data on a number of melts of a new glass called Uviol-Jena.

The transmission curve of this glass coincides closely with that of Helioglass. The transmission at $302 \mathrm{~m} \mu$ (for $t=2.3 \mathrm{~mm}$ ) averages about 58 per cent when new and 43 per cent after exposure to the quartz mercury arc lamp. (Table 2.) The latest importations 52A to $52 \mathrm{D}$ have an appreciably higher transmission, averaging 50 per cent after exposure to the mercury arc lamp. (Table 4.)

\section{ULTRA-VIOLET GLASS}

Through the courtesy of the Ultra-Violet Glass Corporation, New York, we have been able to examine a number of samples of different melts of "Ultra-Violet Glass, U. G." made by the Sendlinger Optical Glass Works, Germany. As shown in Figure 12 the transmission of this glass $(t=2.42 \mathrm{~mm})$ is identical with the sample of Holviglass just described. Exposed to the mercury lamp the transmission at $302 \mathrm{~m} \mu$ decreased from 42 per cent to 31 per cent.

A sample from an earlier melt had a much higher transmission, amounting to 57 per cent at $302 \mathrm{~m} \mu(t=2.1 \mathrm{~mm})$ which decreased to 49 per cent after exposure to the mercury arc. Exposed to the sun in Washington for four months (July to November) the transmission decreased from 57 to 53 per cent. If this record can be maintained, after the process has been standardized, it will mark a real improvement in glasses for transmitting ultra-violet radiation. Samples of more recent manufacture, however, showed an appreciably lower transmission.

Through the courtesy of the Ultra-Violet Glass Sales Co., Chicago, Ill., we are able to include some measurements on several recently imported samples (Nos. 4, 5, 6, 7, Table 4) of this glass.

\section{MISCELLANEOUS NEW GLASSES}

As mentioned in the beginning of this paper, progress in the development of new glasses is so rapid that information can be given only on those kinds that are being actively marketed in this country.

Through the courtesy of importers, especially the Hobbs Manufacturing Co., London, Ontario, Canada, we have been able to obtain data on a number of newly developed ultra-violet transmitting glasses of English, French, and German manufacture.

In all of these glasses, as already observed in Helioglass and Vitaglass, the long wave length side of the absorption band extends into 
the region of $334 \mathrm{~m} \mu$, with transmissions of only 40 to 50 per cent at $302 \mathrm{~m} \mu$ when new, and 30 per cent down to 20 per cent, or even lower, after complete solarization. None of these glasses have the ideal transmission characteristics of quartz glass, Corex-A, and the Locke glass which have a high transmission at $302 \mathrm{~m} \mu$ even after solarization.

We have examined at least one sample of each of the following glasses:

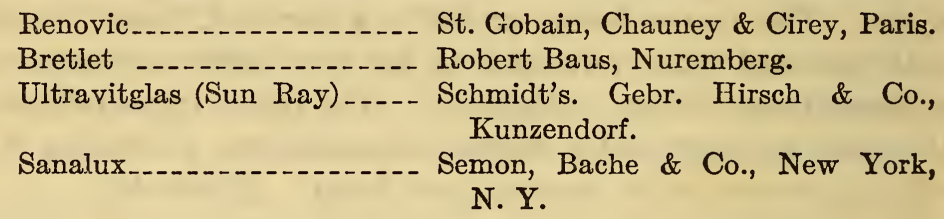

All of these glasses with the exception of Bretlet and Renovic h\&ve ultra-violet transmission curves similar to that of Helioglass (fig. 2) and, when new, they have a transmission of 5 to 15 per cent at $280 \mathrm{~m} \mu, 45$ to 55 per cent at $302 \mathrm{~m}$, and 90 to 92 per cent at $365 \mathrm{~m} \mu$.

Exposed to the sun or to the quartz mercury arc, these glasses decrease in transmission, and, after complete stabilization by exposure to the quartz mercury lamp, the transmission at $302 \mathrm{~m} \mu$ ranges from about 20 per cent for Bretlet and Sanalux, and about 30 per cent for Renovic. More samples of each kind of glass will, of course, be required in order to establish average values. The Neuglas and Sendlinger's Ultra-Violet glass show a distinct advance in the attempts to improve the ultra-violet transparency of window glass. Improvements are also being made in products from the older formulas, as, for example, Helioglass, of which the latest sample examined (in January, 1929) had a transmission of 51 per cent after complete photochemical stabilization by exposure to the quartz mercury arc.

\section{DISCUSSION OF RESULTS ON SOLARIZATION}

In the foregoing pages data are given on the decrease in transmission of ultra-violet radiation through window glasses and substitutes for window glasses as the result of some undetermined photochemical action on exposure to the sun, and to artificial sources or radiation.

The sources used were the sun, which does not contain appreciable radiation of wave lengths less than about $295 \mathrm{~m} \mu$; the carbon arc (without, and with a glass chimney which is opaque to wave lengths less than $310 \mathrm{~m} \mu$ ) which has a fairly continuous spectrum of ultraviolet radiation; and the mercury arc in which the ultra-violet radiation is confined principally to a number of strong emission bands at 254 to $365 \mathrm{~m} \mu$. All of these sources lower the transmission of these glasses and glass substitutes, the unfiltered radiation from the artificial sources apparently causing a somewhat greater decrease in transmis- 
sion than sunlight. This, however, may be owing to the fact that some of these window glasses solarize but slowly and may not have attained a minimum transmission in the time (one year) allotted for making the test. For example, owing to a prolonged delay in sending the foregoing paper to the printer advantage was taken of this status to include further measurements on the solarization of window glasses that has occurred from November 15, 1928, to July 2, 1929 (an additional exposure of 229 days) when the last measurements were made on glasses which are being exposed to the sun in Washington. A still greater change in transmission would be expected during this same length of time if the exposure had been made in the summer months.

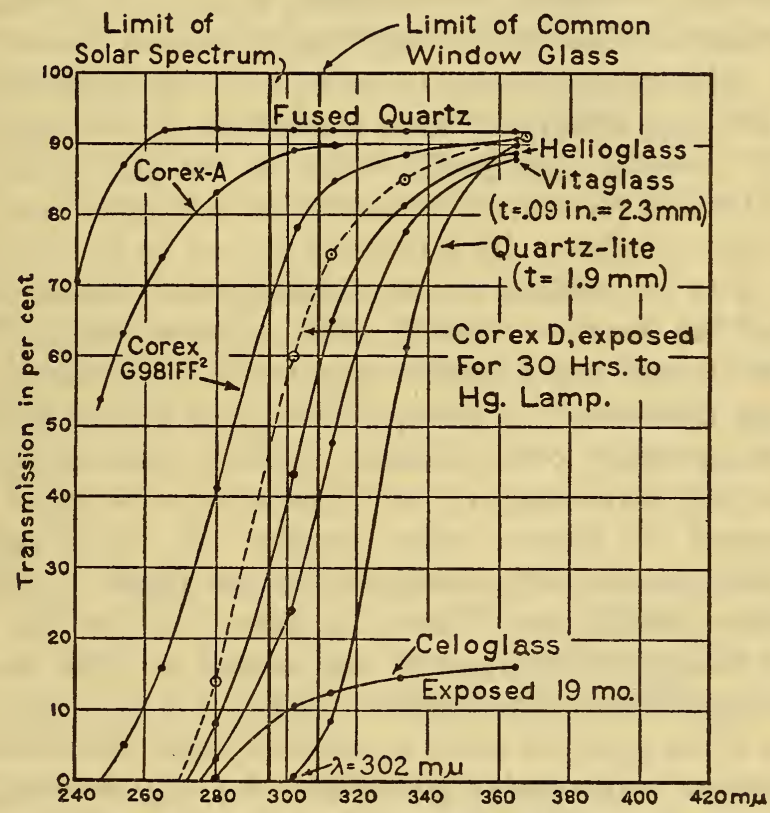

FIGURE 15.-Ultra-violet transmission of various window glasses after exposure to the sun for 12 months (thickness, $t=0.09$ inch $=2.3 \mathrm{~mm}$ )

These new data, which were obtained on Vitaglass, Helioglass, etc., are indicated, by italics in Tables 4 and 5. All these glasses show a further decrease in transmission, which approaches closely the values obtained by exposure to the mercury arc lamp. (See Table 4, Vitaglass $1 \mathrm{~h}$; Helioglass, $5 \mathrm{~h}, 7 \mathrm{~h}$; Holviglass, 1 ; and Sunlit, 3.)

From this it appears that in the course of a few years the photochemical stabilization by solarization will be fairly complete, when the transmission will differ but little from that resulting from exposure to the quartz mercury or carbon arc lamp. This is, of course, in agreement with the observations already described on a sample of Vitaglass which was taken from a hospital window after a year's 
use. On further exposure to the mercury arc lamp the transmission of the sample decreased but little showing that the photochemical stabilization by exposure to sunlight was practically complete. It shows also that the photochemical stabilization by exposure to the sun is practically the same as that produced by the accelerated stabilization by exposure to the unfiltered radiation from the mercury, or the white flame carbon arc lamp, provided that sufficient time is given for the sun's rays to complete the photochemical reaction.

In other words, the photochemical reactions, produced by these three sources of ultra-violet radiation, are brought about by such a wide range of wave lengths that the carbon and the quartz mercury ares may be used to bring to completion, in a relatively few hours, a photochemical stabilization that may require several years of exposure to the sun. This is partly owing to the fact that the short wave lengths (less than $290 \mathrm{~m} \mu$ ) which may have a selective photochemical action, are weak in intensity, and partly owing to the high absorptivity of the material which prevents these short wave lengths from penetrating deeply into the glass. This is easily proved by exposing the glass to the sun or to an artificial source of ultra-violet radiation until the transmission has become constant, then exposing the under side of the glass which produces a further decrease in transmission.

As already mentioned, in most of these new glasses the improvement in transparency over common window glass is obtained by shifting the long wave length side of the absorption band at 290 to $310 \mathrm{~m} \mu$ toward the shorter wave lengths. In other words, these glasses exhibit considerable absorption in the region of $302 \mathrm{~m} \mu$, especially after solarization. Hence, as mentioned in the preceding report (45) biological experiments are needed in order to establish the lowest transmission permissible at 302 to $313 \mathrm{~m} \mu$, after complete solarization of the glass, in order to insure a rapid therapeutic action.

The minimum transmission permissible for effective results manifestly will depend upon the altitude and the latitude of the station. Evidently the most transparent glass available will be required in our northern latitudes where the activating rays are of low intensity, while in localities where sunshine is abundant a glass having a lower transmission may prove satisfactory. The first requirement is therefore a source (or locality in the case of sunlight) having sufficient ultra-violet to prevent rickets; the second requirement is a satisfactory glass to transmit these rays; and the third requirement is proper care of the glass, to keep it clean. It requires but little dust and dirt to reduce the transmission by 40 to 50 per cent. For example, two samples of glass which had been used as windows in an animal house for three months, and which transmitted 17 and 24 per cent, respectively, at $302 \mathrm{~m} \mu$ before washing increased in trans- 
mission to 28 and 40 per cent, respectively, after washing, showing the importance of keeping the windows clean.

The reaction is evidently photochemical involving the presence of a chemically unstable material (especially ferrous iron) as an impurity (46). It is therefore to be expected that different sources may produce different photochemical reactions (at least different amounts of the same kind of reaction), which will continue so long as there is material present that will undergo a photochemical change and so long as the opacity has not increased sufficiently to prevent the rays of various wave lengths from penetrating into the material. As just mentioned, this is easily observed by exposing first one side then both sides of a piece of glass to the arc lamp or to the sun, or by exposing two superposed pieces of glass (say Vitaglass or Helioglass) of single thickness, which is practically equivalent to a piece of glass of double thickness. It is then observed that the transmission of the lower piece (which corresponds practically to the lower half of the thick piece) has decreased far less than that of the upper piece.

That the amount of this impurity and, hence, the amount of depreciation in transmission, varies greatly is shown by the fact that samples of different melts of the same kind of glass, having practically the same thickness, differ greatly in transmission. (Table 4, Helioglass, sample No. $12, t=1.95 \mathrm{~mm}$, tr. $=42.5$ per cent; sample No. $4, t=1.99 \mathrm{~mm}$, tr. $=61.7$ per cent; sample No. $7, t=2.00 \mathrm{~mm}$, tr. $=58$ per cent.)

Our tests on Vitaglass show that after what appears to be a fairly complete solarization by exposure to the sun, when the transmission at $302 \mathrm{~m} \mu$ is down to 20 to 25 per cent an additional exposure to the mercury arc reduces the transmission but little further-18 to 22 per cent. (See Tables 4, 5, and 7.)

In the case of Helioglass (and other recently introduced glasses which solarize but slowly) we have not yet had samples exposed to the sun for a sufficient length of time to make certain that solarization was complete. Extrapolation of the upper curve in Figure 8 indicates a probable minimum transmission of 38 to 40 per cent, whereas, an exposure to the mercury arc reduces the transmission to 39 per cent. From the data given in Table 4 it may be noticed that the unfiltered radiation from the mercury arc reduces the transmission to a value between 35 and 40 per cent, which is about 8 per cent lower than that resulting from exposure to the sun, which from Figure 8 is probably not the minimum.

In the case of the Corex-D and several other newly developed glasses the minimum transmission at $302 \mathrm{~m} \mu$, after photochemical stabilization by exposure to the mercury arc, is decidedly higher than that of Vitaglass and Helioglass. After taking into consideration 
the great variation in the transmission, at $302 \mathrm{~m} \mu$, of various melts of the same kind of glass it seems misleading to make close comparisons in transmissions. Hence, whether we solarize these glasses by exposure to the sun or obtain the photochemical stabilization by exposure to an artificial source of radiation (the mercury arc) containing ultra-violet rays of wave lengths not present in sunlight, the same relative transmissions are obtained. The data presented show also that it is possible to make a glass that will not decrease appreciably in transmission on exposure to the mercury arc or the sun.

It is to be noted that as the result of solarization, the transmission decreases to a permanent value, which, in some of these glasses, is only about one-half the transmission when new. In some of these glasses the transmission, after solarization, is higher than that of the unsolarized earlier products, showing the progress that is being made in the production of glasses having a high transmission of ultra-violet radiation.

In conclusion, it may be stated that, owing to the slowness of some of these glasses in coming to photochemical equilibrium on exposure to the sun, it will require several years to determine whether the accelerated test is too severe. However, the outstanding difference in transmission between the samples of glass subjected to the accelerated test and the duplicate samples which were exposed to the sun is too small to take into consideration. Moreover, all the various makes of glass are comparable on the same basis, whether by accelerated aging with the mercury arc, the carbon arc, or by solarization by exposure to sunlight when the latter exposure is sufficiently prolonged.

\section{EFFECT OF SOLARIZATION UPON THE ULTRA-VIOLET TRANSMISSION OF SUBSTITUTES FOR WINDOW GLASS}

Under this caption are given data on the spectral transmission of substitutes for window glass, especially windows for transmitting ultra-violet solar radiation into animal inclosures, hothouses, coldframes, solariums, etc. Only one material, Celoglass, was extensively investigated for resistance to ultra-violet radiation and the weather.

\section{FLEXOGLASS}

This material (sometimes called glass cloth) consists of a loosely woven cotton cloth (cheesecloth, millinette) which is impregnated with paraffin. The amount of paraffin on the cloth is variable. Hence, the discussion of the optical properties is applicable only in a general way to this material.

Owing to internal reflection among the fibers of the Flexoglass the loss by reflection to the outer surface, facing the sun, is high. As a 
result, the total amount of radiation transmitted to the interior of the inclosure is rather low. By placing the sample directly over the thermopile receiver it was found that about 35 per cent of the incident ultra-violet light from a quartz mercury arc (filtered through Corex-G. 986A) was diffusely transmitted. This value increased as the material softened and became more translucent when it became heateda property that is observed when the cloth is exposed to the sun.

In Figure 16 is given the spectral transmission of the radiation traversing linearly through the cloth which was placed over the entrance slit of the spectrometer. This reduces the total intensity by a greater. amount than would be observed when the sample is placed over the thermopile at the exit slit (29). But the latter procedure is subject to errors from heating of the material by the absorbed radiation (which material then radiates to the thermopile) and by diffuse light

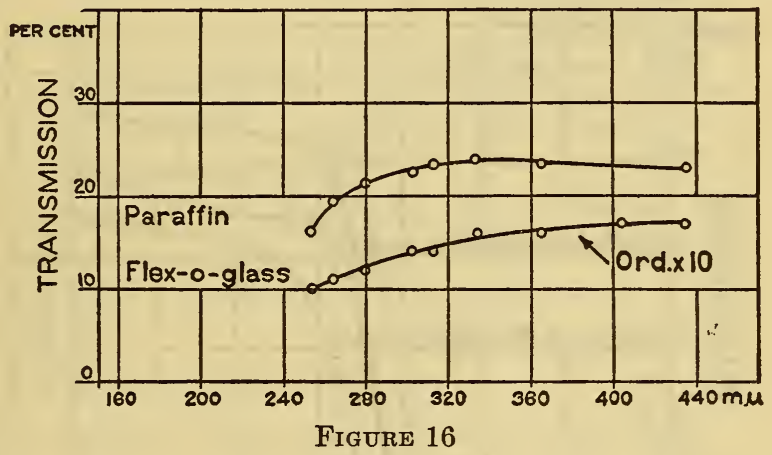

from the adjacent part of the spectrum which passes through the exit slit and falls upon the thermopile.

As shown in Figure 16, a thin layer of solid paraffin (between two plates of quartz) is uniformly transparent throughout the ultra-violet part of the spectrum which is of interest in therapeutic work. A similar uniform but much lower transmission (fig. 16) was observed through (the interstices of) the Flexoglass cloth.

Whether the amount of ultra-violet solar radiation transmitted by this material is sufficient for therapeutic purposes, especially in the winter when these activating rays are most needed, is a problem in biology that will require further investigation. The tests already made (30) seem to show that the transmission of the activating solar radiation is too low to be useful therapeutically and that because of its tendency to soften in the sun, and hence, retain dust, this material is to be considered primarily only as an inexpensive temporary protection for use in animal husbandry in winter. 


\section{CELOGLASS}

The material sold under this trade name consists of a film (of variable thickness) of cellulose acetate on a wire mesh. The solvents of cellulose commonly used are acetone, ethyl lactate, and triphenyl phosphate.

In the material now on the market the wire mesh obstructs about 30 per cent of the incident light. Hence, not taking into account absorption and internal reflection in the cellulose film, the maximum amount that can be transmitted through Celoglass (cellulose acetate) is only about 60 per cent of the incident solar radiation. In the visible, and in the long wave length ultra-violet, where there is but little selective absorption, the observed transmission is fairly uniform, amounting to about 35 to 45 per cent at $400 \mathrm{~m} \mu$, depending upon the thickness of the film. The difference between the observed (35 to

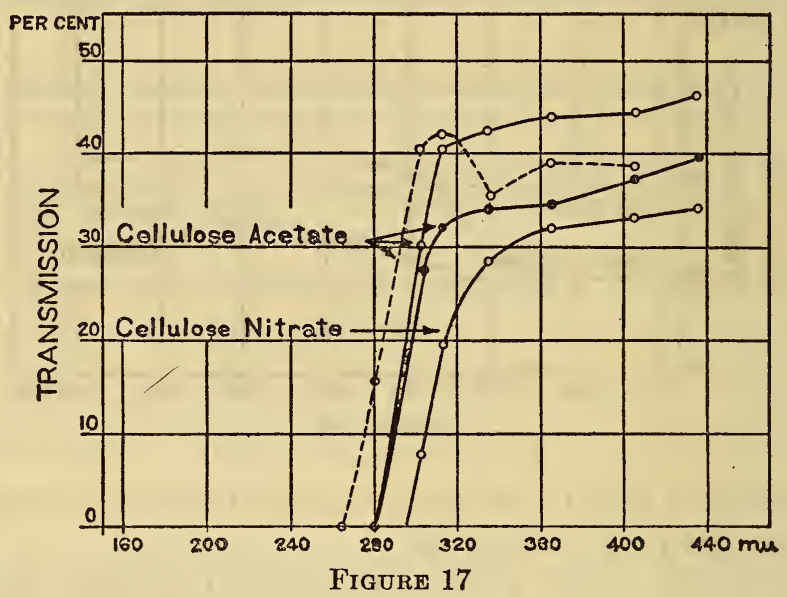

45 per cent) and the calculated value (60 per cent) is to be ascribed to absorption and diffusion of the light.

The cellulose material examined was the nitrate and the acetate. The cellulose nitrate was brittle and as shown in Figure 17, even when new, it was practically opaque to wave lengths less than $300 \mathrm{~m} \mu$. The cellulose acetate was less brittle and it was transparent to $280 \mathrm{~m} \mu$ in the ultra-violet. In a previous paper (31) we have given the transmission of thin homogeneous films of pure cellulose (viscose rayon) and cellulose acetate (celanese rayon). In that paper it is shown that pure cellulose has a high transmission throughout the ultra-violet to $250 \mathrm{~m} \mu$. (Fig. 18.)

As shown in Figures 17 to 23, when new, Celoglass (cellulose acetate film) transmits, rectilinearly, 25 to 35 per cent at $302 \mathrm{~m} \mu$, and, hence, an average of about 25 per cent of the total incident vitalizing ultra- 
violet solar rays which are absorbed by window glass. This average value of 25 per cent refers to the rays that are not deviated from their original direction in passing through the material. The total amount passing through the Celoglass, including the (scattered, diffused) rays deviated from their incident path would be about 5 per cent higher, or an average transmission of 30 per cent at $302 \mathrm{~m} \mu$. (See Table 2.) This was determined by the screen method described in B. S. Jour. Research (RP6), 1, p. 105; 1928; in which the wave lengths of about $365 \mathrm{~m} \mu$ were isolated by means of a filter of Corning glass, G586J. In this manner it was established that the total amount

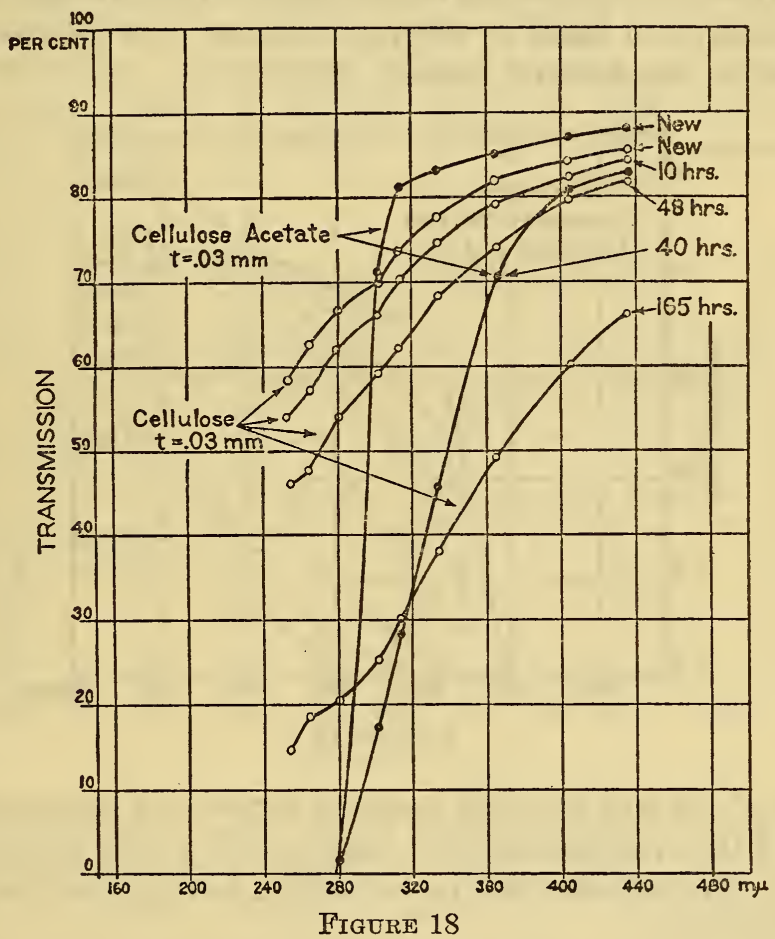

of radiation transmitted diffusely through Celoglass (average of five samples) was 52 per cent, whereas only 40 per cent of the rays of wave lengths $365 \mathrm{~m} \mu$ were transmitted directly into the spectrometer.

As shown elsewhere (29) in cases where great optical homogeneity and freedom from scattering of the light is not essential, the amount of vitalizing rays transmitted by this material (at least when new) is sufficient to have a beneficial effect in animal husbandry. However, the transparency is greatly decreased by the deposition of dust, and, hence, the length of time that a given sample of this material can be used on animal houses will depend upon the prevalence or absence of dust. 
We have found consiaerable variation in ultra-violet transmission of different samples of this material, when new; also a difference in their behavior when exposed to sunlight and to artificial light.

Early in this investigation it was found that there is a marked differeace in the aging of Celoglass depending upon the method of acceleration, whether $(a)$ by exposure to artificial light, $(b)$ by exposure to direct sunlight, or $(c)$ by exposure to the weather, day and night, either under the eaves of a building or directly in the open.

In the sunlight tests it was observed that, when first exposed, some of the samples increased somewhat in transparency at $280 \mathrm{~m} \mu$. This is, no doubt, owing to the evaporation of the solvents which have a strong absorption band at $280 \mathrm{~m} \mu$, whereas pure cellulose is fairly transparent in this spectral region. (Fig. 18.)

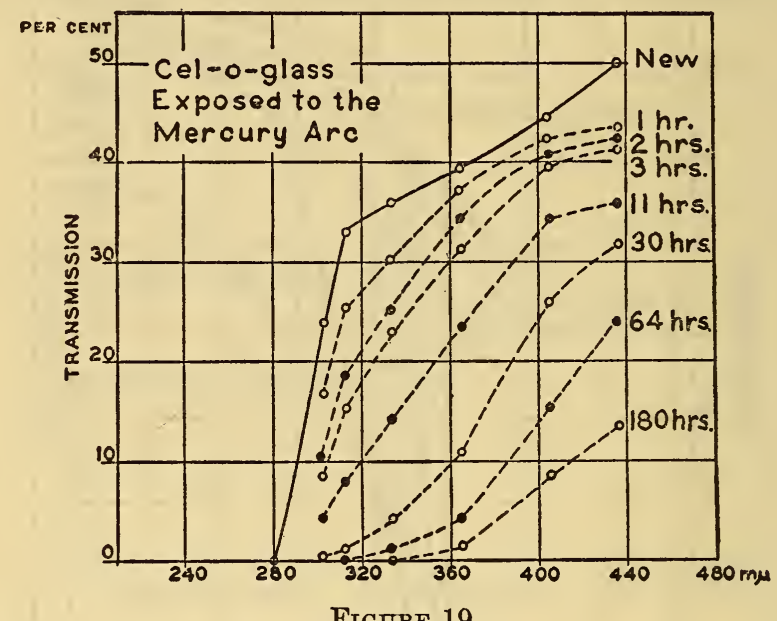

Figdre 19

In view of the fact that this material is not very homogeneous it is to be noted that the transmission data recorded refer to the rays that entered the spectrometer slit, no correction having been made for the loss by scattering.

(a) ACCELERATED AGING UNDER ARTIFICIAL LIGHT

As just mentioned the accelerated aging of Celoglass, by exposure to the quartz mercury arc, which is strong in ultra-violet rays not present in solar radiation, is different from the photochemical aging that results from exposure of this material to sunlight. These short wave length ultra-violet rays produce a rapid photochemical change in the cellulose compound so that an exposure of a few hours reduces the ultra-violet transmission to practically zero, and, hence, the material is but little better than common window glass, although to the eye the color developed is barely perceptible. On further exposure 
the cellulose is tinged a yellowish brown. This change in transmission is illustrated in Figure 19 which is interesting in showing the rapid decrease in transmission in the short wave lengths, whereas in the long wave lengths the decrease in transmission with age is less rapid. This effect is practically the same for the cellulose nitrate and cellulose acetate films on the wire mesh and is in agreement with previous observations (32) of the effect of ultra-violet light upon films of cellulose.

\section{(b) EXPOSURE TO SUNLIGHT}

In this test the samples were mounted side by side on a block of wood and exposed at normal incidence to the solar rays between the hours of $9 \mathrm{a}$. m. and $4.30 \mathrm{p} . \mathrm{m}$. during the months of April to October, 1927. The mounting was adjusted several times a day in order to maintain the rays closely at vertical incidence upon the samples. During cloudy weather and during the night these samples were kept in the laboratory.

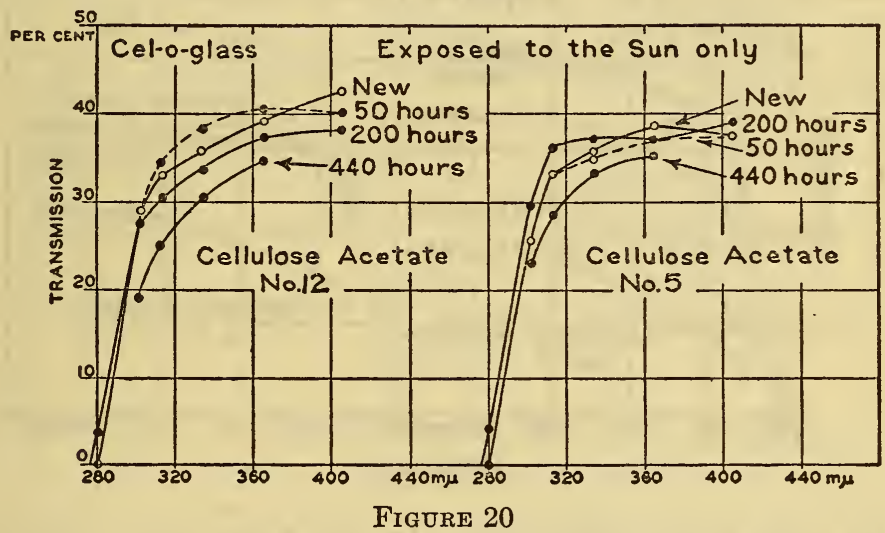

As shown in Figure 20, aside from a slight increase in transparency at $280 \mathrm{~m} \mu$, on first exposure, which is no doubt owing to evaporation of the solvent, exposure to sunlight has only a slow action in decreasing the transparency of (Celoglass) cellulose acetate. It is interesting to note that after 200 hours' exposure of the Celoglass to sunlight the accelerated aging under the mercury arc continued in the same manner as on samples which had not been seasoned in the sun.

\section{(c) EXPOSURE TO THE WEATHER}

The effect of varying weather conditions upon the transparency of Celoglass is clearly illustrated in Figure 21 which shows the change in transmission of two samples (Nos. 5 and 9) of cellulose acetate exposed side by side continuously day and night at an angle of $45^{\circ}$, facing south, from April 1 to December, 1927. From this illustration and Figure 20 it may be seen that sample No. 5, which was not 
greatly affected by sunshine, decreased continuously in spectral transmission when exposed to the weather day and night, and, hence, probably became valueless for transmitting ultra-violet therapeutic rays after nine months' usage. In contrast with this is sample No. 9 (also a cellulose acetate) which changed but little in ultra-violet transmission during the first five months of exposure to the weather. This, however, was an unusual sample which, on first exposure to the mercury arc lamp, decreased in transmission to a constant value; at which level it remained even after prolonged exposure to the lamp.

On further exposure to the weather this sample showed a marked decrease in transmission, probably owing to accumulation of dust and smoke, which increased in the fall and winter months.

In Figure 22 is shown the effect of aging upon a Celoglass sample No. 6 which was exposed continuously and simultaneously witb samples Nos. 5 and 9 (fig. 21), but in another part of the city which

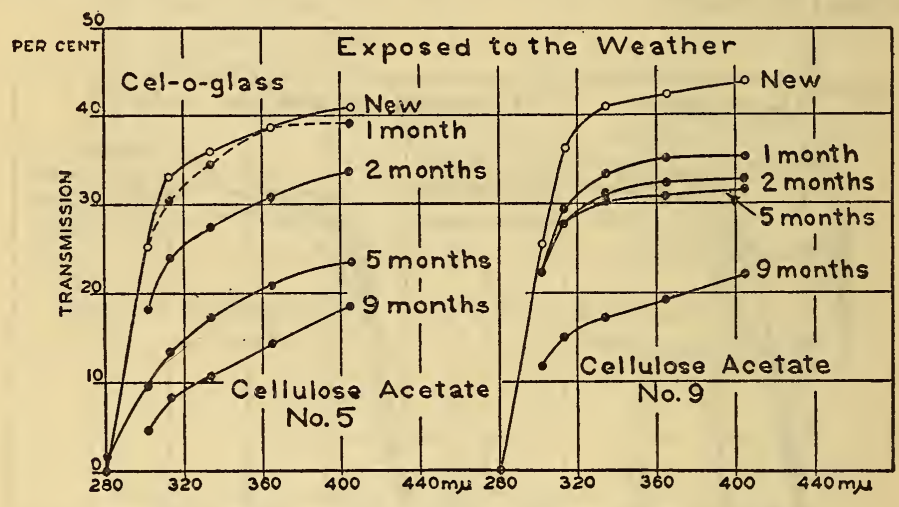

FIgURE 21

was free from dust, smoke, etc. In this case, after three months' exposure, the transparency of sample No. 6 at $280 \mathrm{~m} \mu$ was actually higher than when new, although there was a decrease in transmission in the longer wave lengths. The explanation given to us by a competent authority is that the whitish (powdery) film which forms on the surface of the cellulose acetate when exposed to the weather is blown away by the wind, thus decreasing the thickness of the film. This probably accounts for the fact that after an exposure for nine months to the weather this sample was full of holes.

In addition to the decrease in thickness, we have to consider also the evaporation of the solvents (fig. 20), which have a high absorption for wave lengths less than $300 \mathrm{~m} \mu$.

In contrast with the samples (fig. 20 ) which were exposed only to the sun, in Figure 23, sample No. 3 shows the effect of exposing the material in a locality free from dust, in the south window of a large building with overhanging eaves and window frames so that but little, 
if any, rain fell upon the Celoglass. In this sample the transmission changed but slowly after being exposed two months, and even after nine months, judging from biological tests (29) the transmission (23 per cent at $302 \mathrm{~m} \mu$ ) is still sufficiently high to be usefulfor therapeutic purposes. After an exposure through 2 summers (19 months) the transmission at $302 \mathrm{~m} \mu$ was 10 per cent. From this it may be seen that when used on the side of a building having a wide overhanging roof the deterioration of Celoglass by the weather is greatly retarded.

In Figure 22 is shown the spectral transmission curves of new and of old samples of cellulose nitrate which had been exposed to the weather and then submitted to us for examination. The cellulose nitrate, especially after esposure to the weather for two months, does not appear to transmit sufficient ultra-violet (see fig. 17 for another sample) to be of interest therapeutically, and hence need not be discussed.

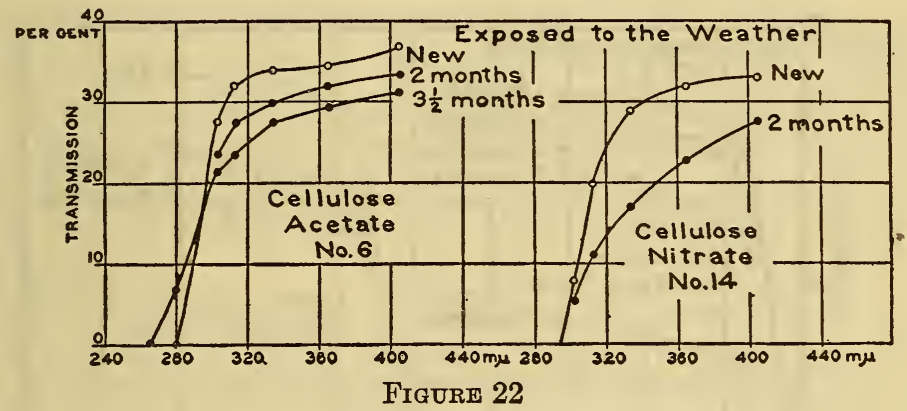

In Figure 23 the Celoglass sample No. 13 is of interest because sample No. 13-C, which had been out in the weather for four months, and had become covered with dirt, was more opaque than the fairly clean sample, No. 13-B (said to have been taken from the same roll as No. 13-A) which had been exposed for two years. While this may seem anomalous it is easily explained on the basis of the presence or absence of dust and smoke in the atmosphere and of the amount of protection from overhanging eaves, etc., as we have found by actual test.

From the foregoing tests, on material placed out of doors only on clear days it is shown that direct sunlight has only a slow effect upon the aging of Celoglass. On the other hand, the combined effect of sunlight and the varying atmospheric conditions (also dust) have a marked effect in decreasing the ultra-violet transmission of (Celoglass) cellulose acetate. As a result, the transmission of ultraviolet solar radiation of short wave lengths is greatly decreased (fig. 15 ) and in some cases the material probably becomes valueless for therapeutic purposes. 
In view of the fact that it is recognized that summer weather deteriorates this material, it is recommended to be used in poultry houses, etc., during the winter months, and removed during the summer months.

\section{CELLOPHANE}

As shown in Figure 18 pure cellulose (viscose rayon, cellophane, protectoid) is highly transparent throughout the ultra-violet. Recently Pfund (33) has proposed the substitution of cellophane in place of the usual window glass. For this purpose he suggested using large sheets of the material which are to be mounted between two pieces of wire mesh.

Our tests show that cellophane undergoes a large shrinkage ( 8 to 12 per cent) on exposure to the weather for a few months. Hence, it will be necessary to provide for this decrease in size, if it is to be used in frames as described by Pfund.

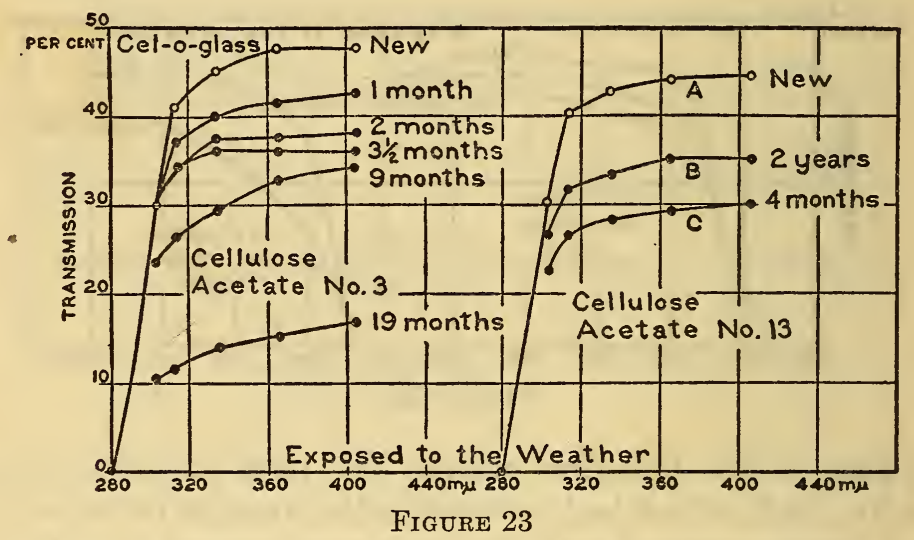

Cellophane appears to solarize, but slowly, on exposure to the weather. In fact, owing to evaporation of the solvent or plasticiser the transmission may actually increase during the first fow weeks of exposure; for example, one sample, $0.14 \mathrm{~mm}$ in thickness, that was exposed from July to October, 1928, shrank about 12 per cent in length and increased in transmission from an initial value of 38 to a final value of 58 per cent at $302 \mathrm{~m} \mu$.

\section{POLLOPAS, ALDUR, GELATIN}

The newly discovered condensation products of formaldehyde and urea (trade names Pollopas, Aldur) when entirely colorless have a high transmission throughout the ultra-violet (34). However, a slight brownish discoloration introduced in the preparation of the material, or as the result of solarization, greatly reduces the transmission in the ultra-violet. 
The sample of Aldur examined by us had a fairly high transmission (about 32 per cent for $t=2.5 \mathrm{~mm}$, surface uneven) at $302 \mathrm{~m} \mu$.

Recently Crist (35) published data on a sample of Aldur (36) $3 \mathrm{~mm}$. in thickness, which transmitted about 66 per cent at $302 \mathrm{~m} \mu$. Exposure to the mercury arc for 18 hours reduced the transmission at $254 \mathrm{~m} \mu$ from 48 to 40 per cent.

Recently we have tested the transmission of a film of a gelatin product, mounted on a wire mesh, similar to Celoglass. The material examined had a transmission similar to that of cellophane (fig. 18) with a characteristic absorption band at $280 \mathrm{~m} \mu$ with a high transmission at $250 \mathrm{~m} \mu$. Whether gelatin has any weathering qualities was not determined.

\section{TRACING CLOTH}

In view of the publicity given to the discovery that ordinary tracing cloth transmits short wave length ultra-violet radiation, tests were made on this material.

Tracing cloth consists of thin, loosely woven fabric of linen or cotton impregnated with a soluble, transparent starch. The drawback in the use of such a material, as a window, is the high solubility of the sizing, which dissolves when touched with water, leaving the cloth in a rough condition which is then no better than that of other thin, bleached, loosely woven material, such as, for example, nainsook or balloon cloth.

We have determined the transmission of tracing cloth by the methods described in B. S. Research Paper No. 6 (vol. 1, p. 105; 1928), and find that the total ultra-violet of wave lengths 250 to 310 $\mathrm{m} \mu$ diffusely transmitted through a new sample of tracing cloth amounted to 25.9 per cent before wetting the glossy surface, and 14.2 per cent after removing the sizing and drying the cloth. In the publication just cited (B. S. Research Paper No. 6, Table 1) are recorded the ultra-violet transmissions of a sample of balloon fabric (tr. $=21$ per cent), of batiste (tr. $=16$ per cent) and of nainsook (tr. $=31$ per cent) showing that tracing cloth is not superior to other fabrics for use as a window for transmitting ultra-violet radiation.

\section{CONCERNING THE USE OF WINDOWS}

In a foregoing caption it was deduced that for air mass $m=1$, the amount of short wave length ultra-violet solar radiation that has the property of preventing rickets amounts, at the most, to perhaps about $0.004 \mathrm{~g}$ cal. $/ \mathrm{cm}^{2} / \mathrm{min}$.

This is an appreciable amount when considered in terms of full sunlight at the noon hour in summer. Within a properly constructed solarium, glazed with the most transparent material obtainable (quartz glass), about 90 per cent of the 302-region of ultra-violet

$73113^{\circ}-29-5$ 
solar radiation (or about $0.0036 \mathrm{~g}$ cal.) would be transmitted in the summer and, owing to the greater air mass $(m=2.5)$ traversed, less than 10 per cent of this value (less than $0.00036 \mathrm{~g}$ cal.) would be available in winter. (Fig. 1.)

The question of the amount of skylight and sunlight that can enter through a vertical opening (a window of a house) is important to the house owner. In this connection the curves published by Kimball and Hand (17) showing the amount of sunlight and daylight coming through a vertical opening (a window), on all sides of a house, at different hours of the day and different seasons of the year, are especially instructive and worthy of study by architects and heliotherapists.

From our direct measurements, supplemented by the photometric measurements of Kimball and Hand, we deduce that, in the wintertime (December), the maximum amount of short wave length ultraviolet solar radiation that can enter a vertical opening (a window glazed with quartz glass) facing south would be less than $0.00036 \mathrm{~g}$ cal. $/ \mathrm{cm}^{2} / \mathrm{min}$., and through a north window it would be less than $0.0001 \mathrm{~g} \mathrm{cal} . / \mathrm{cm}^{2} / \mathrm{min}$., decreasing, of course, to an imperceptible amount at sunrise and at sunset. For, as shown by Pettit, (18), at Mount Wilson, it is only during the five or six hours through the middle of the day that an appreciable amount of these activating rays is transmitted through the atmosphere. He has photographed the solar spectrum down to $293 \mathrm{~m} \mu$ (47).

In this connection, it is relevant to cite some of our direct measurements on the ultra-violet radiation from the north sky, which were made by Method IV (but using a 12-junction Bi-Ag thermopile) described in a preceding caption. On an exceptionally clear, cloudless day (March 18, 1929, see fig. 1) at the noon hour the short wave length ultra-violet from ( $85^{\circ}$ of) the north sky, amounted to 0.00029 g cal. $/ \mathrm{cm}^{2} / \mathrm{min}$., as compared with $0.0033 \mathrm{~g} \mathrm{cal} . / \mathrm{cm}^{2} / \mathrm{min}$. from the direct solar radiation, or about one twenty-fifth of the short wave length ultra-violet in June. (Fig. 1.)

The shortest wave length observed in December by Dorno (19) at Davos, Switzerland (elevation 5,300 feet), was at about $308 \mathrm{~m} \mu$. $\mathrm{He}$ found that the short wave length ultra-violet solar radiation atmidday in July, as measured with a cadmium photoelectric cell, was ten times greater than in January -in agreement with the thermocouple measurements in Figure 1. The advantage of the thermocouple over the photoelectric cell is in the ease with which it can be calibrated to obtain the measurements in absolute value.

Recent investigations by Bundesen (20) and his collaborators show that in our smoke-laden cities but little ultra-violet radiation of wave lengths less than $297 \mathrm{~m} \mu$ is transmitted to the earth's surface in 
summer, while in the three winter months the shortest wave length transmitted was at about $303.5 \mathrm{~m} \mu$.

Owing to the difficulties in preventing fogging of the photographic plate on long exposures, it is difficult to photograph the extreme limit of the solar spectrum. However, sufficient data appear to be at hand to show that even at the noon hour in winter but little, if any, ultra-violet solar radiation of wave lengths less than about $305 \mathrm{~m} \mu$ is transmitted to the earth's surface, especially in large industrial cities.

If, in addition to atmospheric absorption, the rays must pass through a glass which transmits only 25 to 30 per cent of these rays (or less than about $0.0001 \mathrm{~g}$ cal. through a north window) the intensity appears to be close to the threshold value for therapeutic purposes. This conclusion follows from the observations of Tisdall and Brown (21), who obtained practically no healing effects from the light of the sky at a distance of 3 feet or more from an average-sized window, under conditions similar to those found in the average home.

Their observations, which were made in August, show that in the latitude of Toronto $\left(43.6^{\circ}\right)$ the light of the sky shining through an ordinary-sized window, whether glazed with special glass or covered with ordinary fly screen, had practically no effect in preventing rickets in animals except immediately adjacent to the window (that is, an exposure to the whole sky), and that in order to obtain real benefit it is necessary to receive the direct rays from the sun. Furthermore, they found (22) that, while during the winter months (December, January, and February) the ultra-violet rays produced a slight, but definite antirachitic effect (which was only about one-eighth as great as in April and May), the use of special window glasses in that locality during the winter months is probably of little value. As is to be expected, their work shows that in order to obtain a useful antirachitic effect from sky shine (that is, solar rays reflected from the sky and clouds) approximately equal to that of the direct rays of the sun, it is necessary to construct a solarium of special glass which will admit rays from a large part of the sky.

The most recent and important data, which, no doubt, will settle the question of placing windows of special glass on the north side of school and office buildings, were published by Clark (23). The observations were made in a large room on the seventh floor with a north exposure. During perfectly clear days, at noon, in March and April, when the illumination from the hemisphere of north sky incident upon the window sill was approximately 400 foot candles (in good agreement with the measurements of Kimball and Hand, already mentioned), the illumination in the center of the room, $5 \mathrm{~m}$ from the window was 10 foot candles. The conclusion was that if the room were equipped with ultra-violet-transmitting glass windows, a child, 
located in the center of the room, would have to sit there for 20 hours in order to obtain as much untra-violet radiation as it would receive in two minutes out of doors in sunlight at the noon hour. In May, it would be necessary to sit there for 15 hours in order to get the equivalent of two minutes of direct noon sunlight. But since only during five to six hours at midday an appreciable amount of ultra-violet is transmitted through the atmosphere, it would be necessary to sit for three days to obtain the benefit of two minutes of direct noon sunlight. The usefulness of such glasses in solariums is admitted, but Doctor Clark states that a better solution of the problem is to get out of the schoolroom and the office at the noon hour.

Further evidence supporting these conclusions was recently published by Eddy (24) who found that, in order to prevent rickets, the animals under test had to be kept directly in the path of the sun's rays. Those animals that were $1 \mathrm{~m}$ or more from the window, or close to the window, but outside of the path of the sun's rays developed rickets.

All the evidence available at present indicates that for the treatment of invalids a solarium glazed with special window glass is necessary in order to obtain beneficial results in preventing rickets and presumably for general therapeutic purposes.

During the year, and during the day, the sun's rays vary greatly in their angle of incidence upon the solarium. In this connection it is of interest to determine the loss of light by reflection from the surface and the loss by absorption in traveling through the glass, both of which increase with the angle of incidence.

The results of this inquiry show that for normal incidence of the solar rays, the loss by reflection amounts to a little less than 10 per cent, increasing to about 12 per cent for an angle of incidence of $i=45^{\circ}$, about 15 per cent for $i=55^{\circ}$, and about 20 per cent for $i=60^{\circ}$. Similarly the optical path of a glass $2.0 \mathrm{~mm}$ in thickness and having a refractive index of $n=1.56$ is about $2.2 \mathrm{~mm}$ for an angle of $45^{\circ}$ and about $2.40 \mathrm{~mm}$ for $i=60^{\circ}$. Since, for glasses which transmit 30 to 50 per cent of the vitalizing rays, an increase in thickness of $0.1 \mathrm{~mm}$ increases the absorption by about 1.2 per cent, the maximum increase in absorption of the glass would amount to about 5 per cent. Hence, the additional loss by reflection and absorption at the maximum angle of incidence as compared with that at normal incidence, would be about 25 per cent (certainly less than 30 per cent) which is of minor importance in comparison with the question of keeping the glasses clean, and other factors, such as dust and smoke, which greatly absorb the vitalizing rays.

In connection with the foregoing discussion, it is relevant to include data on the use of heavy, wired glass, which is of importance for safety in the case of breakage, when used on a sloping roof. From 
calculation on samples of glass which, for a thickness of $2.3 \mathrm{~mm}$, transmit only 20 to 30 per cent, and from direct observations it is found that thick (6 mm, one-fourth inch wired) samples of this type of glass transmit only 3 to 5 per cent at $302 \mathrm{~m} \mu$. In a previous communication (25) it was shown that this transmission is too low for biological use. Hence, if thick samples must be used, for safety, then it is necessary to use material that has little or no absorption at $302 \mathrm{~m} \mu$. Otherwise, it will be necessary to use single thickness $(2.3 \mathrm{~mm}=0.09$ inch) glass backed with a $1 \mathrm{~cm}$ wire mesh which shuts out about 10 per cent of the total light.

Another item usually overlooked in connection with the usefulness of these glasses is the importance of keeping the surfaces clean and free from dust. It requires but little contamination of the surface of the glass to decrease the transmission by 10 per cent or even more. For example, the unwashed parts of samples obtained from an animal house in a zoological park transmitted only 30 to 40 per cent as much as the adjacent parts that were cleaned before examination. When one considers that after solarization some of these glasses transmit only 20 or 30 per cent, it is evident that the windows must be kept clean in order to obtain beneficial results, especially in northern latitudes and in smoke-laden cities where the ultra-violet solar rays are almost entirely absorbed, especially in the wintertime when most needed.

This conclusion is based upon a study of a report issued by the Council of Physical Therapy (26) of the American Medical Association, which shows that only those glasses and glass substitutes which had a transmission of 30 per cent, or higher, at $302 \mathrm{~m} \mu$ gave an appreciable protection against rickets, but this protection was not 100 per cent.

Recently we have tested an ultra-violet transmitting glass which was used in front of a carbon arc lamp to shut out the rays of wave lengths less than $280 \mathrm{~m} \mu$. After 300 hours' use, it was observed that the patients, who were being irradiated by this lamp, no longer responded properly to the light treatment. Our tests showed that the glasses, which were 2.6 to $2.7 \mathrm{~mm}$ in thickness, transmitted only 15 to 20 per cent at $302 \mathrm{~m} \mu$ (Table 7), in comparison with about 45 per cent when new. The conclusion seems inevitable that this loss in therapeutic efficiency was owing to the decrease in transmission of the special window glass by the action of the ultra-violet rays.

Further evidence on this question is contained in a communication by Wyman (27) in which he shows that only glasses having a high transmission (for example, Corex-A and fused quartz) admitted sufficient ultra-violet solar radiation for the rapid improvement of rickets in children in Boston during the wintertime. 
As mentioned elsewhere in this paper, in most of these new glasses the improvement in transparency over common window glass is obtained by shifting the long wave length side of the absorption band at 290 to $310 \mathrm{~m} \mu$ toward the shorter wave lengths. Moreover, for glasses $2.3 \mathrm{~mm}$ in thickness and transmitting 30 to 50 per cent, a change in thickness of only $0.1 \mathrm{~mm}$ changes the transmission by about 1.2 per cent. Many of these glasses exhibit considerable absorption in the region of $302 \mathrm{~m} \mu$, especially after solarization. Hence, as mentioned in the preceding report (28), biological experiments are needed to determine the lowest transmission permissible at 290 to $302 \mathrm{~m} \mu$ in order to obtain a rapid therapeutic action. In this connection the recent tests of Caldwell and Dennet (50) in New York City may be cited. They find that, as a preventative measure, exposures must be made in the direct path of the sun's rays.

The minimum transmission permissible for effective results manifestly will depend upon the altitude and the latitude of the station. Evidently the most transparent glass available will be required in our northern latitudes where the activating rays are of low intensity, while in localities where sunshine is abundant a glass having a lower transmission may prove satisfactory. The first requirement is therefore a source (or locality in the case of sunlight) having sufficient ultra-violet to prevent rickets; the second requirement is a satisfactory glass to transmit these rays; and the third requirement is proper care of the glass, to keep it clean.

In view of the misconceptions regarding the properties of window glasses it is relevant to add that these new window glasses possess no mysterious healing powers, and that no window glass, or substitute for window glass, can add short wave length ultra-violet rays to compensate for those that are lacking in sunlight. On the other hand, as shown in the foregoing pages, a glass window may greatly reduce the intensity of the short wave length ultra-violet rays that are present in sunlight. Hence, whenever it is possible, it is better to utilize direct sunlight instead of that which is transmitted through a window.

\section{SUMMARY}

This paper deals with three fundamental questions, (a) the amount of ultra-violet in solar radiation of wave lengths less than about 310 $\mathrm{m} \mu$, found to be of especial use in preventing rickets, but shut out by common window glass, $(b)$ the decrease in transmission that occurs in the newly developed window glasses for transmitting ultra-violet of wave length less than about $310 \mathrm{~m} \mu$, when exposed to ultra-violet radiation, and (c) the proper use of windows in order to obtain the most effective therapeutic results.

(a) By four methods of attack, data were obtained showing that the upper limit of the total amount of ultra-violet solar radiation, of wave 
lengths less than about $310 \mathrm{~m} \mu$, is less than $0.004 \mathrm{~g}$ cal. $/ \mathrm{cm}^{2} / \mathrm{min}$. at sea-level stations.

(b) It is shown that nearly all these newly developed window glasses decrease in transmission, especially in the ultra-violet of wave lengths less than $310 \mathrm{~m} \mu$, when exposed to the sun and to artificial sources containing ultra-violet radiation. In some makes of glass there is practically no decrease in transmission as the result of photochemical aging; other glasses lose almost one-half their transparency at $302 \mathrm{~m} \mu$ in the process of photochemical stabilization.

(c) Concerning the use of windows, data are given showing that, with variation of the angle of incidence of the solar rays from normal upon the solarium, during the year and during the day, the amount transmitted through the glass decreases by about 20 per cent. The necessity of keeping the glasses clean is indicated by the observations that dust and dirt reduce the transmission at $302 \mathrm{~m} \mu$ by 30 to 40 per cent.

Double thickness (one-fourth inch, $6 \mathrm{~mm}$ ) wired glass, even when made of these newly developed materials (except, perhaps, Corex-D and pure quartz glass) after complete photochemical stabilization, transmits only 3 to 5 per cent at $302 \mathrm{~m} \mu$, which is probably too low for therapeutic use. Hence, a glass of single thickness $(t=2.5 \mathrm{~mm})$, with a wire mesh under it for safety from breakage, is recommended for solarium roofs.

\section{REFERENCES}

1. Coblentz, B. S. Letter Circular No. 235 (September 1, 1927); 2d rev., September 29, 1927; 3d rev., January 14, 1928. The present communication supersedes this letter circular.

2. Coblentz, Spectral Characteristics of Light Sources and Window Materials Used in Therapy, I. E. S., convention, Chicago; September, 1927; Trans. Illum. Eng. Soc., 23, p. 247; 1928. Coblentz, Summary Data on the Transmissibility of Ultra-Violet Radiation through Glasses and Glass Substitutes used for Therapeutic Purposes, Trans. of the Twenty-fourth Annual Meeting of the Nat. Tuberculosis Assn.; 1928. Coblentz and Stair, The Effect of Solarization Upon the Ultra-Violet Transmission of Window Materials, I. E. S. convention, Toronto, September, 1928; Trans. Illum. Eng. Soc., 23, p. 1121, 1928.

3. Heilbron, Kamm, and Morton, J. Chem. Soc., London, 263, p. 2000; 1927. Wyman, Am. J. Diseases of Children, 34, p. 733; 1927. Bills, Honeywell, and Cox, J. Biol. Chem., 80, p. 557; 1928.

4. Coblentz and Kahler, B. S. Sci. Paper No. 378, 16, p. 233; 1920.

5. Coblentz, B. S. Sci. Paper No. 413, 17, p. 187; 1921.

6. Coblentz, B. S. Bull. No. 282, 13, p. 423; 1916.

7. Hess and Weinstock, J. Am. Med. Assn., 80, p. 687; 1923; Proc. Soc. Exptl. Biol. and Med., 24, p. 759; 1927; Hess and Anderson, J. Am. Med. Assn., 89, p. $1222 ; 1927$.

8. Sonne and Reckling, Hospitalstidend, 70, p. 399; 1927. See also Maughan Am. J. Physiol., 87, p. 381; 1928.

9. Coblentz, Trans. Illum. Eng. Soc., 23, p. 287; 1928. 
10. See illustration in Figure 13, of a previous publication by Coblentz, Trans Illum. Eng. Soc., 23, p. 287; 1928.

11. Coblentz and Kahler, B. S. Sci. Papers No. 378, 16, p. 235; 1920.

12. Coblentz, B. S. Sci. Papers No. 438, 17, p. 725; 1922.

13. Coblentz, Dorcas, and Hughes, B. S. Sci. Paper No. 539, 21, p. 535; 1926.

14. The selection of these glasses is described in the preceding paper: Coblentz, Trans. Illum. Eng. Soc., 23, p. 278; 1928.

15. In the preliminary announcements (Coblentz, Dorcas, and Hughes, B. S. Sci. Paper No. 539, 21, p. 535; 1926) a value of 2 per cent was given, but this referred to wave lengths less than $1,400 \mathrm{~m} \mu$. Correcting for the water cell (tr. $=78.5$ per cent) the value is 1.6 per cent of all wave lengths.

16. Transmission given in B. S. Sci. Paper No. 438, 1\%, p. 734; 1922.

17. Kimball and Hand, Mo. Weather Rev., 50, p. 615; 1922.

18. Pettit, Publ. Astronom. Soc., Pacific, 38, p. 21; 1926.

19. Dorno, Strahlentherapie, 18, p. 72; 1924. Jüngling (cited by Mayer, Clin. Applications of Sunlight) observed the shortest wave length at $307 \mathrm{~m} \mu$ in January and $295 \mathrm{~m} \mu$ in July.

20. Bundesen, Lemon, Falk, and Coade, J. Am. Med. Assn., 89, p. 187; 1927.

21. Tisdall and Brown, Am. J. Diseases of Children, 34, p. 742; 1927.

22. Tisdall and Brown, Am. J.' Diseases of Children, 34, p. 721; 1927.

23. Janet H. Clark, Science, 68, p. 165; August 17, 1928.

24. Eddy, Science, 68, p. 13; October 19, 1928.

25. Coblentz, Trans. Illum. Eng. Soc., 23, p. 247; 1928.

26. Reported in the J. Am. Med. Assn., 88, p. 1562; 1927.

27. Wyman, Boston, Med. J., September 5, 1927.

28. Coblentz, Trans. Illum. Eng. Soc., 23, p. 290; 1928.

29. See similar data in J. Am. Med. Assn., 88, p. 1562; 1927.

30. J. Am. Med. Assn., 88, p. 1567; 1927.

31. Coblentz and Stair, B. S. Jour. Research, 1 (RP6), p. 106; 1028.

32. Coblentz and Kahler, B. S. Sci. Paper No. 342, 15, p. 215; 1919.

33. Pfund, J. Am. Med. Assn., 91, p. 18; 1928.

34. The Transmission of Follopas is described in B. S. Tech. Paper No. 369, 22, p. 573; 1928.

35. Crist, Ind. Eng. Chem., 20, p. 1367; 1928.

36. From the Luco Products Corporation, Brookiyn, N. Y.

37. Revised table taken from B. S. Letter Circular No. 235, 3d rev., issued January 14, 1928.

38. Goodman and Anderson, Boston Med. and Surg. J., 19\%, p. 1316; 1928. Similar data published by Starkie and Turner (Trans. Soc. Glass Tech., 12, p. 308; 1928) confirm our measurements. They say (p. 315) "Quartzlite had the smallest transmission of the glasses examined, being very little better than ordinary window glass."

39. See the recent paper by Starkie and Turner (Trans. Soc. Glass Tech., 12, p. $324 ; 1928)$ on the influence of ferric oxide on the ultra-violet light transmission of soda-lime-silica glass.

40. This question is being investigated over an extended range of temperatures by A. Q. Tool and R. Stair, Glass Ind., 9, p. 51; 1928.

41. In B. S. Letter Circular No. 235, 3d rev., January 14, 1928, it was reported that two samples each of Helioglass and Vitaglass exposed simultaneously to the sun were found to have decreased in transmission at about the same rate, but this does not seem to be the general rule for prolonged exposure.

42. Coblentz, B. S. Sci. Paper No. 438, 1\%, p. 735; 1922.

43. Coblentz and Stair, B. S. Tech. Paper No. 369, 22, p. 573; 1928. 
44. Further data on quartz glass are given in B. S. Tech. Paper No. 369, 22, p. 577; 1928.

45. Coblentz, Trans. Illum. Eng. Soc., 23, pp. 287 and 290; 1928.

46. By removing the iron oxide from the sand used in making the glass the transparency of ordinary (soda lime) window glass is greatly increased at $302 \mathrm{~m} \mu$.

47. Pettit, Trans. Nat. Tuberculosis Association; 1928.

48. Clark, Am. J. Hygiene, 9, p. 646, May; 1929.

49. Bethke and Kennard, Poultry Science, 6, p. 290; 1927.

50. Caldwell and Dennet, J. Am. Med. Assn., 92, p. 2088; 1929.

51. Fleming, The Military Surgeon, p. 592; May, 1928.

52. Russell and Massengale, Poultry Sci., 7, p. 85; 1928.

53. Fabry and Buisson, Compt. Rend., 175, p. 156; 1922.

54. Fabry and Buisson, Astrophys. J., 54, p. 297; 1921.

Washington, March 21, 1929 